\title{
تحليل عمل المرشد التربوي في المدارس الثانوية
}

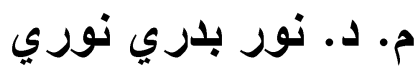

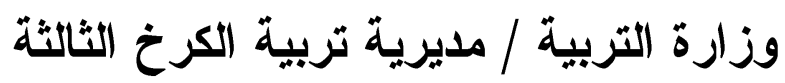

Ybnah1@1e.ac.uk

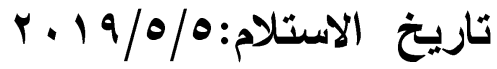

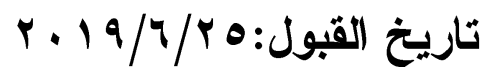

\section{(c) $(\mathrm{i}$}

This work is licensed under a Creative Commons Attribution 4.0 International License.

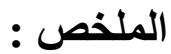

هدف البحث الحالي الى تحليل عمل المرشـد التربوي في المدارس الثانوي في مدينة بغداد ولتحقيق هذا

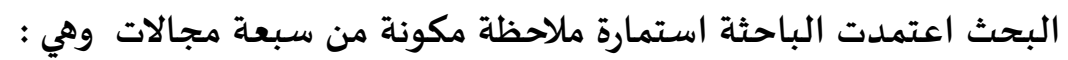

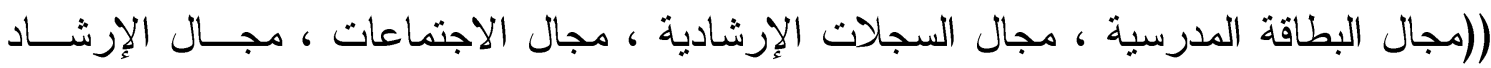

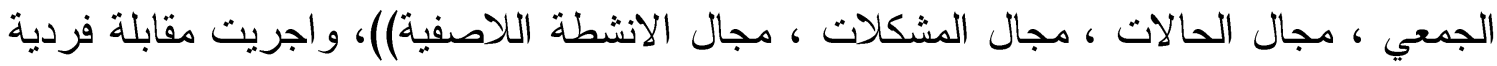

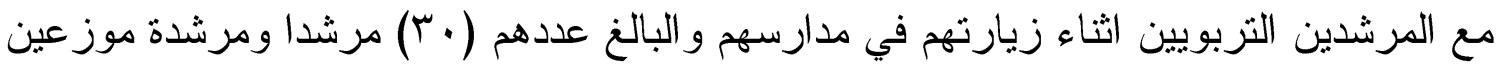

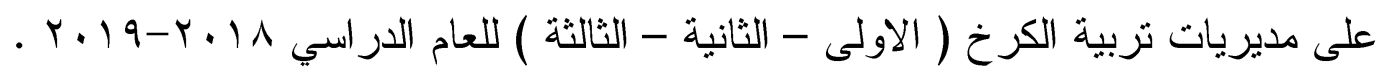
توصلت الباحثة الى اهم النتائج : ملاحظات تدرج أهمها الآتي: التئي ا. احتلت المشكلات اليومية الجزء الأكبر من وقت المرشد التربوي داخل المدرسة وذلك لأنها

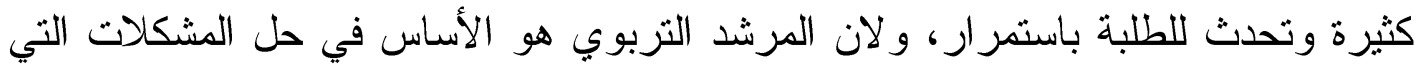
يمر بها الطلبة على مدار السنة لذلك يلجؤون الإن الئه.

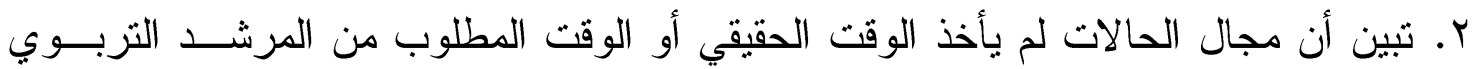

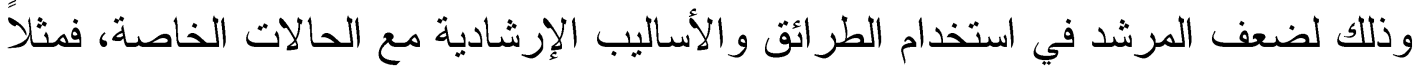

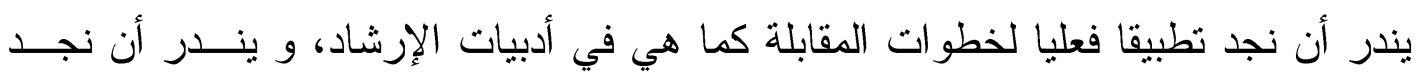

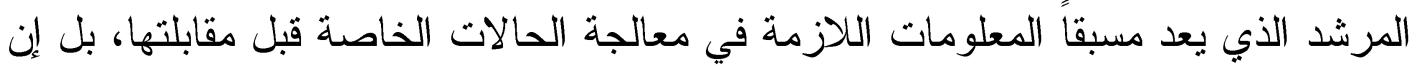
اغلب المرشدين يستخدمون الأساليب التقليدية في معالجة الحالات.

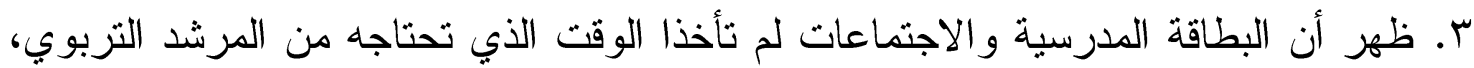
فالبطاقة المدرسية أصبحت قديمة وغير فعاله فهي لا نو اكب التغييرات وبحاجة الى تعـديل

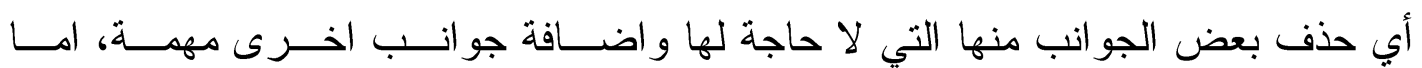
الاجتماعات فإنها قليلة لان ضيق الوقت يحد من عقد الاجتماعات. 
ا ـ توصي الباحثة الجهات المسؤولة عن العمل الإرشادي بمتابعة عمل المرشد والاهتمــام

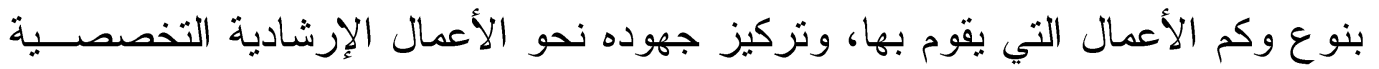

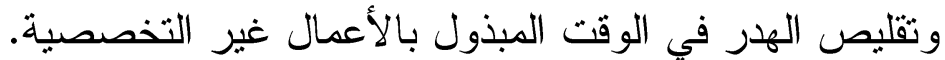

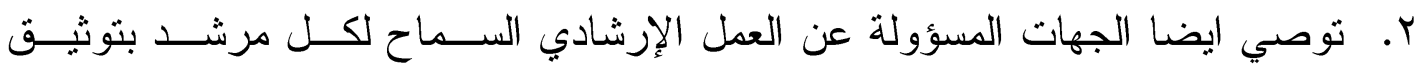

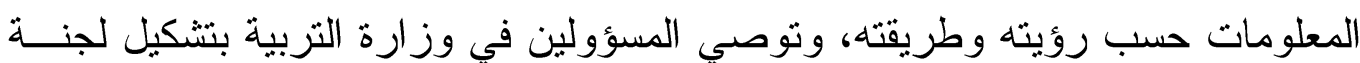

$$
\begin{aligned}
& \text { من الإرشاد لتعديل البطاقة المدرسية بما يناسب التغيرات الحاصلة. } \\
& \text { الكلمات المفتاحية : تحليل عمل ، المرشد التربوي ، المدارس الثانوية }
\end{aligned}
$$

\section{Analysis of the Work of the Educational Advisor in Secondary Schools Dr. Noor Badri Nuri Ministry of Education/ Directorate of Education Al-Karkh III Ybnah1@le.ac.uk}

\section{Abstract}

The aim of the current research is to analyze the work of the educational advisor in the secondary schools in the city of Baghdad and to achieve this research, the researcher adopted a note form consisting of seven areas:

((Field of school card, field of guidance records, meeting area, Field of collective guidance, field of cases, problem area, area of extra-curricular activities)). An individual interview was conducted with the educational advisors during their visit to their schools, their number is (30) male and female advisors distributed in the Educational Directorates of Karkh (1st-2nd-3rd) for the academic year 20182019.

The researcher reached the most important results:

The most important notes include the following:

1- The daily problems have dominated the majority of the educational advisors' time within the school because they are frequent and occurred to students constantly, and because the pedagogical advisor is the basis for solving the problems that students are going through throughout the year, so they turn to him.

2- It turns out that the field of cases did not take the real time or the time required of the educational advisor because of the weakness of the advisor in the use of techniques and methods of guidance with special cases, for example we rarely find the actual application of the interview steps as they are in the guidance literature, and we rarely find the advisor who prepared beforehand the information needed to deal with special cases before interviewing them, and even the majority of advisors use traditional methods in treating the cases.

3- It appeared that the school card and the meetings did not take the time you need from the educational advisor, because the school card has become outdated and ineffective it does not keep up with the changes and needs to modify any deletion of some aspects of it and not needed and add other important aspects, but the meetings are few because the lack of time limits the holding of meetings.

The researcher recommended:

1- The researcher recommends that the authorities responsible for the work of the guidance to follow the work of the advisor and to pay attention to the type and 
quantity of his work, and focus his efforts towards specialized guidance work and reduce waste in the time of non-specialized work.

2- She also recommends that the authorities responsible for the guidance work to allow each advisor to document information according to his knowledge and method, and recommends the officials of the Ministry of Education to form a committee of guidance to amend the school card to suit the changes that have occurred.

Key Words: Analysis of the Work, Educational Advisors, Secondary Schools

أولاً : مشكلة البحث :

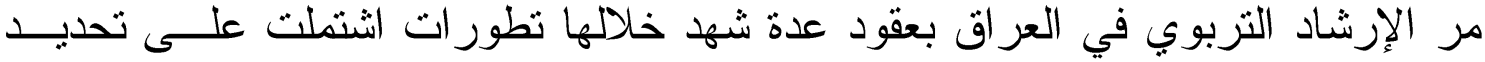

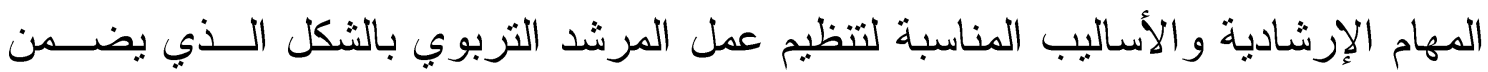

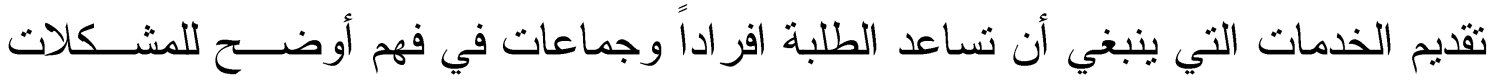

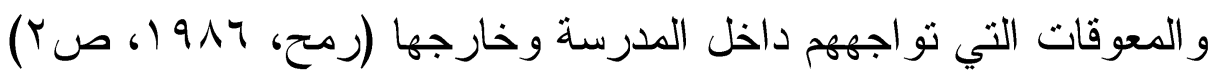
.(Ramah, 1986, P2)

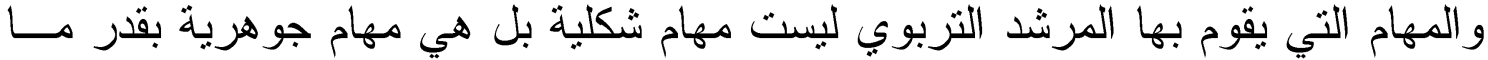
يشعر المرشد بمسؤوليتها، لذلك برزت الحاجة إلى التعرف و عن قرب عن نــوع المهــام و الوقت الفعلي المبذول فيها من المرشدين التربويين بالمدارس المشمولة بالإرشــاد مسنـ خلال الملاحظة المباشرة للمرشد أثناء أداء مهامه أو الإعمال التي بقوم بها خلال الــدوام وتوثيق ما يجري داخل المدرسة لإعطاء صوره حقيقية للعمل الفعلي الذي يقوم به المرشد و التي بسفر عنها للتحليل، و لان البحوث السابقة التي تعنمد على أسلوب التقــدير الـذاتي بالإجابة على الاستبيان لا تعطي صوره حقيقة لأداء المرشد التزبــوي لمهامــهـ داخـلـ المدرسة فقد بصف المرشد عمله بغير ما راه الآخرون.

ومن خلال عمل الباحثة في مجال التربية و التعليم و لا سيما مهنة الإرشاد التربوي ثرى أن مشكلة البحث الحالي تتبلور في الضعف بتطبيق المهام الإرشادية بشكلها السـليم داخل المدارس، بسبب قلة الإمكانات المتاحة داخل المدرسة فضلاً عن ذلك قلة فهم بعض المدر اء و التدريسيين بدور المرشد التربوي وقلة تعاون بعض أولباء الأمور مع المرشــــ أثناء مو اجهة أو لادهم بعض المشكلات (در اسية، سلوكية، نفسية، صحية) داخل المدرسة.

ثانياً : أهمبة البحث

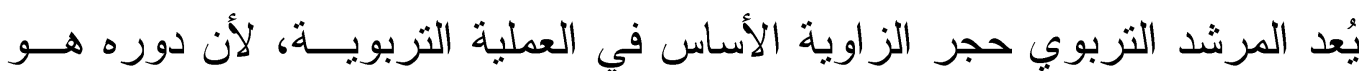
الأكثر نأثثراً من المدير و المدرس في الطالب، فهو يقوم بالاهنمام بالطلبة ويـؤدي دوراً 
بارزاً في مساعدتهم في استيعاب سلوكياتهم والآثار المنزتبة عليها، ويقدم لهم الإرشادات الضرورية لتغير أو تعديل بعض النو احي في سلوكهم و التي تؤدي بهم إلى المشكلات .( Saleh, 1995, P65)

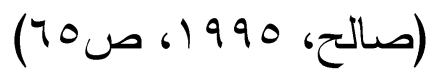

وبما أن لشخصية المرشد النزبوي تأثيرها في تعديل سلوك الطلبة، لذا ينبغي أن

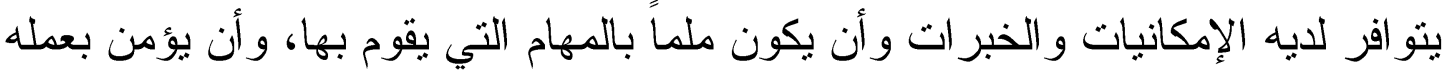

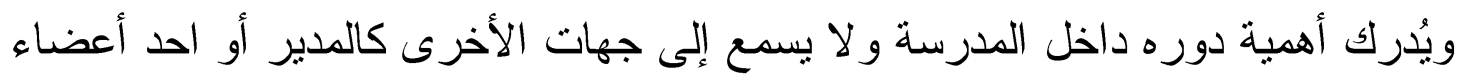

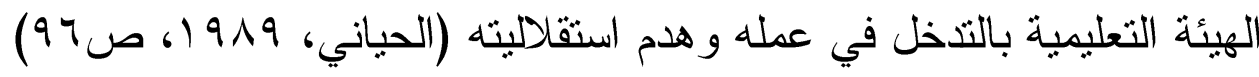
.(Hayani, 1989, P96)

و لتحليل العمل أهمية كبيرة ، فهو يزودنا بالمعلومات التي بمكن الافادة منهــا فـي

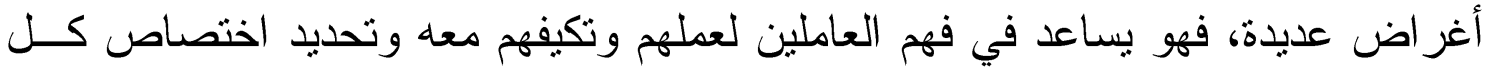

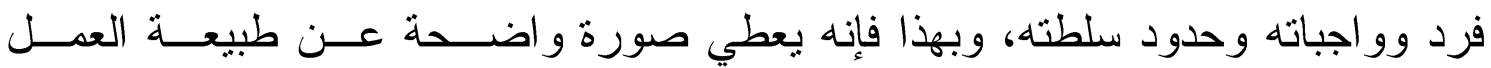

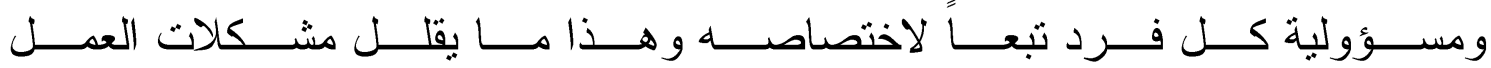

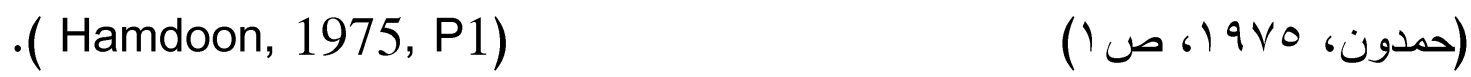
وقد يساعد هذا البحث الجهات المسؤولة في وزارة التزبية على التعرف عن كثب

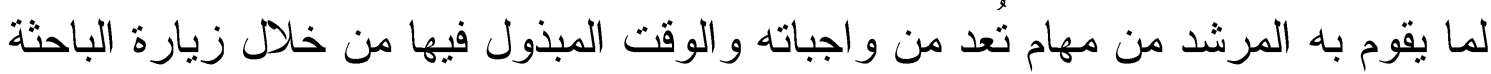

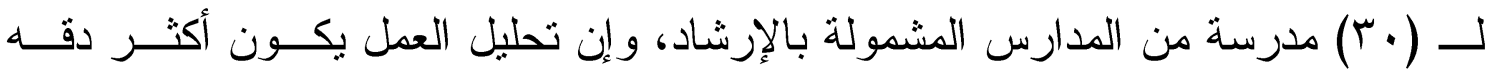

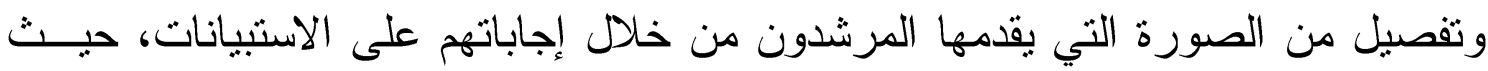
يمكن الاستدلال بشكل موضوعي عن الأعمال التي يقوم بها المرشد التربوي ون والأعمــال

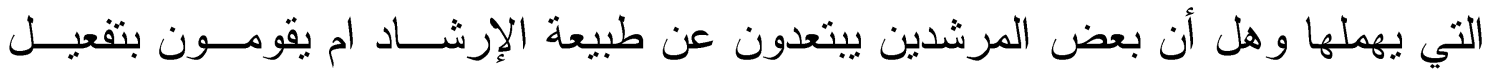

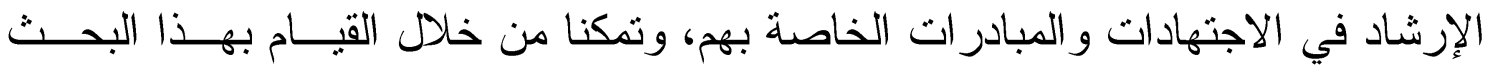
التعرف على الصعوبات التنظيمية للههام الني يقوم بها المرشد كما هي بالو اقع الميــداني و هذا بساعدنا في التفكير في تطوير بعض المهام و إلغاء مهام أُخرَ. ثالثاً : هدف البحث :

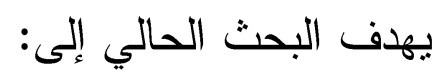
تحليل عمل المرشد التزبوي في المدارس الثانوية في مدينة بغداد. 
رابعاً: : حدود البحث

يتحدد البحث الحالي بالمرشدين و المرشدات العـاملين فــي المــــارس الثانويـــة

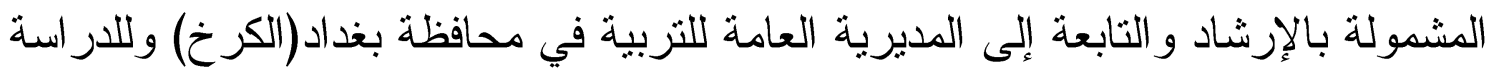

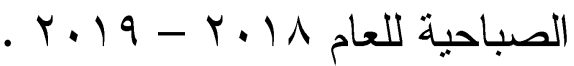

خامساً : تعدبِ مصطلحات البحث

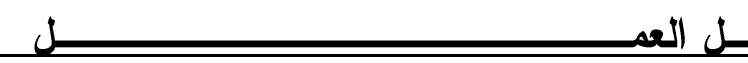

يمكن تعريف تحليل العمل كما يأني: -التجميع المنظمّ لبيانات أساسية تتعلق بالو اجبات التي نكوِّن عملاً ما و المتطلبات العقلية

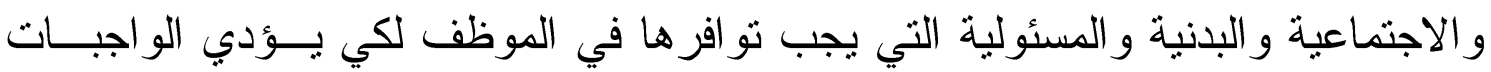
بنجاح (http://abouzied2010.mam9.com/t14-topic) تعريف وزارة التربية للمرشد التريوي 1911

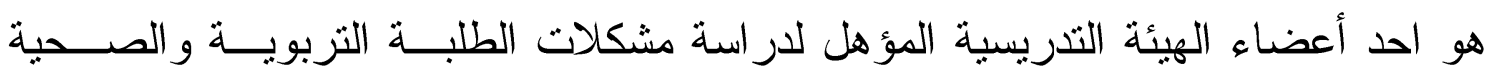
و الاجتماعية و السلوكية عبر جمع المعلومات الني تتصل بهذه المشكلات سواء أكانت هذه

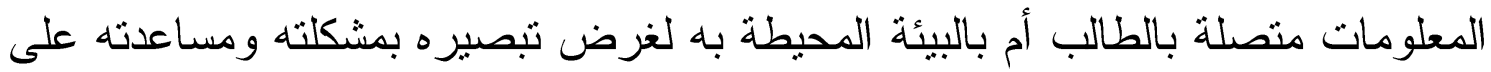

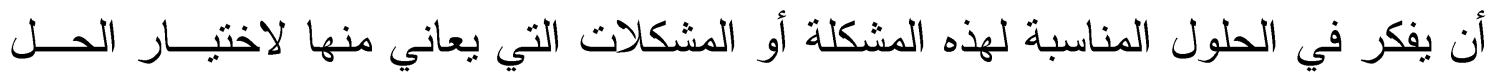

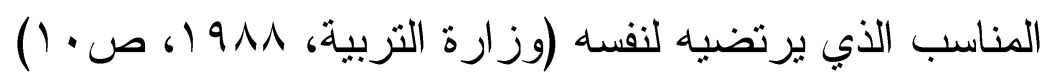
.( Ministry of Education, 1988, P10)

ولقد تبنت الباحثة تعريف وزارة التربية للمرشد التزبوي.

الإطار النظري ودراسات سابقة

أولاً : مفهوم الإرشاد النفسي والتريوي

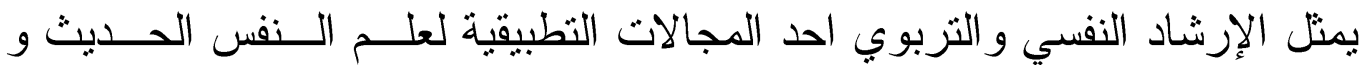
يهدف إلى تطور الانسان وتحقيق سعادته، " فالإرشاد هو العملية التي تساعد الانسان في

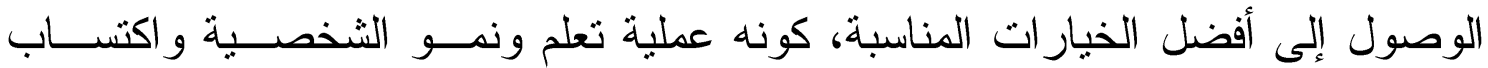
معلومات ذاتية وسلوك أكثر فاعلية يمكن أن يترجم إلى فهم أفضل لدور الانسان" (طاهر

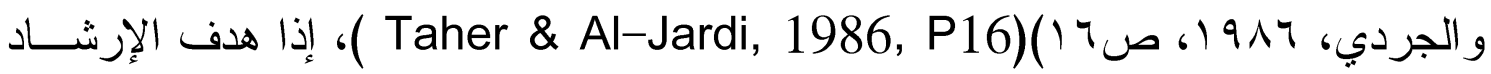
هو مساعدة الفرد الى فهم نفسه وقدر اته و إمكاناته عن طريق علاقة و اعية مخططة نهدف 
للوصول به إلى الرضا وتجاوز المشكلات التي يعاني منها من خلال دراسته الثخصــية

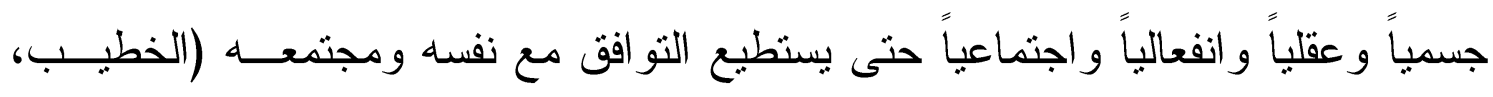

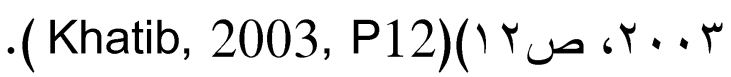

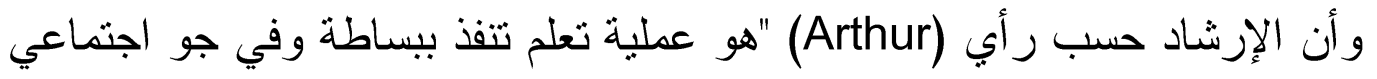

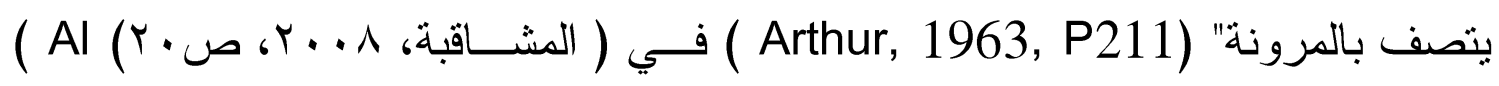

.Mashaqbah, 2008, P20) ومن خلال ما ذُكر فإن الإرشاد هو احد قنوات الخدمة النفسية الني تقدم للأفر اد أو الجماعات بهدف التغلب على بعض الصعوبات التي تعثرضهم ونعوق نو افقهم و إنتاجهم. ثانياً : أهمية الارشاد التريوي الغرض من الإزشاد التزبوي هو تقديم المساعدة للطلبة عندما نو اجههم مشــكلات نربوية تعيق مسيرة تقدمه العلمي، و دور الإرشاد هو الأخذ بأبديهم في حل مشـــاتلاتهم وتشجيعهم على مواجهة تلك المشكلات من خلال معرفة الطالب لحالته كفرد له شخصيته

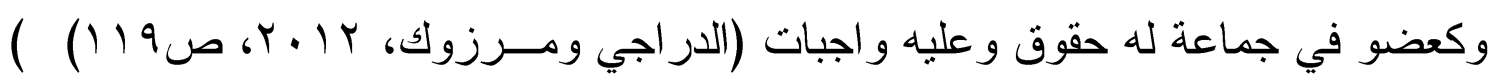
.Darraji \& Marzouk, 2012, P119) وللمرشد التربوب دور مهم في توجيه طلاب المدارس الثانوية التي نعد الطالــب هابـ

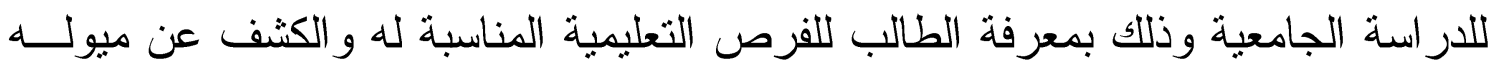
و استعداداته، وتتحقق أهداف الطلبة عن طريق تعاون البيت و المدرسة وتتسيق العمل في مر احل التعليم المختلفة، ويجب أن يدرك المرشد وكذلك أعضاء هيئة التنديس مسؤولياتهر

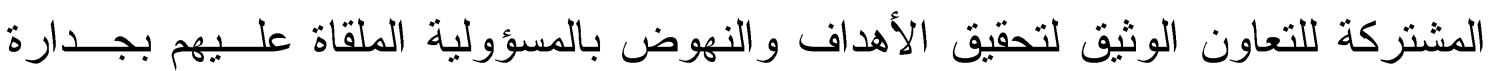

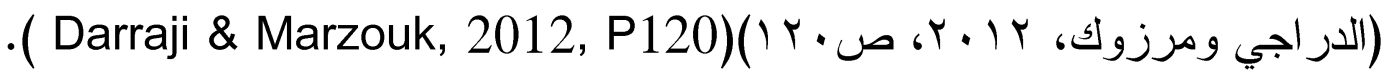
فالظروف التي تحيط بالإنسان من تغير اجنماعي سريع ومنو اصل، وتفجير سكاني

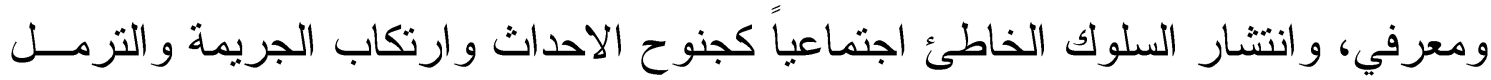
و الطلاق و غيرها، كل هذه عو امل تجعل الإنسان بحاجة الى الإرشاد. وتكمن أهمية الإرشاد النفسي في المدرسة إلى تحقيق ما يأني: 


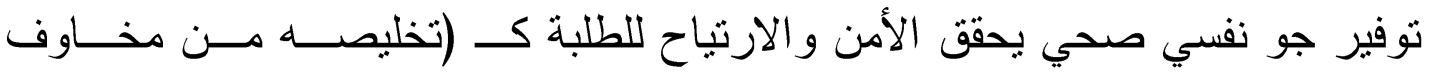

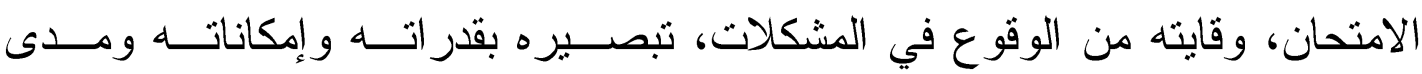
(استثمار ها).

إثارة دافعية الطلبة للار اسة وتتظيم أوقاتهم لها. تعليم الطلبة السلوك الاجتماعي و العمل بروح الفريق و احتر ام الاخرين. • تعليم الطلبة تحمل المسؤولية الثخصية في اختيار القرار . مساعدة الطلبة في اختيار التخصص الدراسي المناسب.

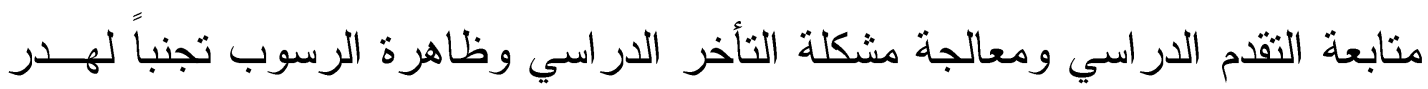
الطاقات التعليمية.

\section{ثالثاً : المرشد ودوره في تحسين العملية التريوية}

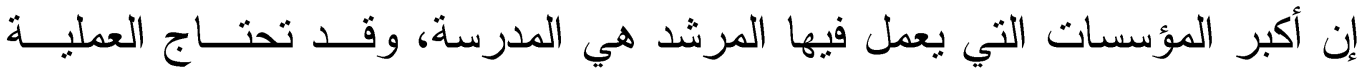
التربوية داخل المدارس إلى تحسين مسنمر قائم على نوفير جو ملائم لنمو شخصية الطلبة

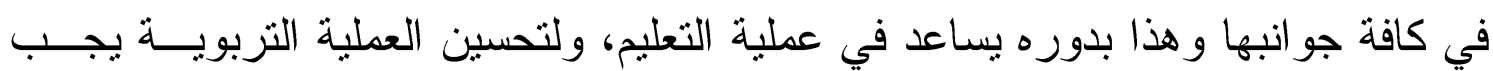

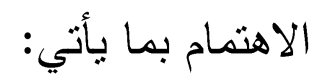
إثارة الدافعية وتشجيع الرغبة في التحصيل. مر اعاة الفروق الفردية بين الطلبة.

مساعدة الطلبة وجعلهم قادرين على التعبير عن ذاتهم ومو اجهة مثــكلاتهم واتخــاذ

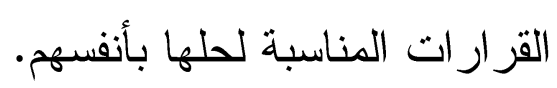

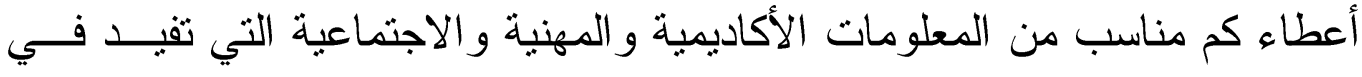

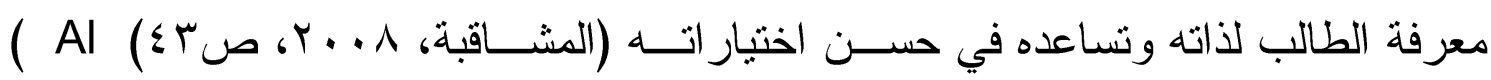
.Mashaqbah, 2008, P43) وبما أن المدارس بحاجة الى البرنامج الإرشادي المدرسي هذا بعني انها بحاجــة

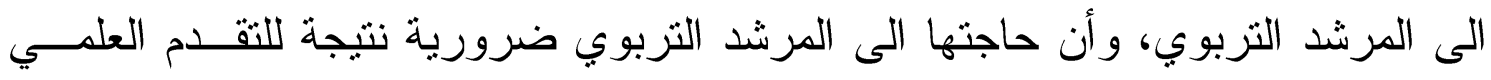

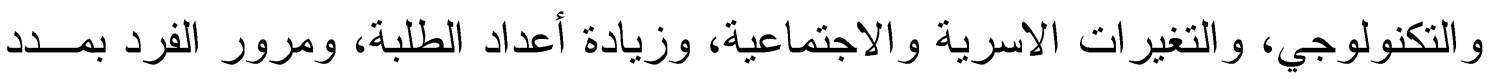

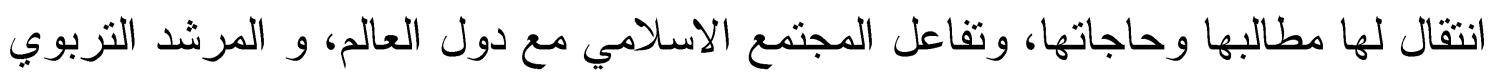

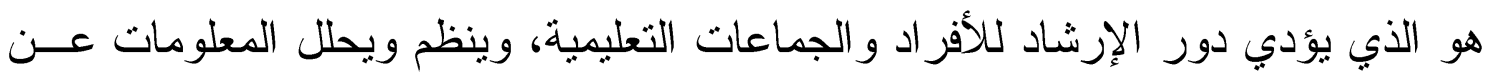


الطلاب من السجلات و الاختبار ات و المقابلات وذللك لتقييم ميولهم واتجاهاتهم وقـدر اتهم

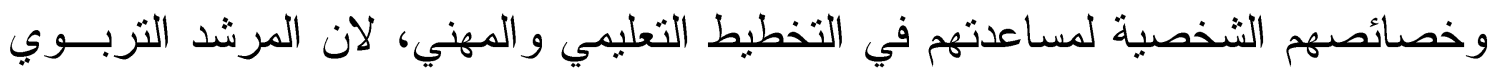

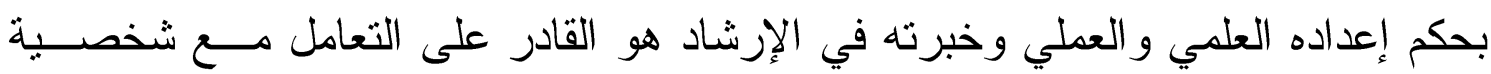

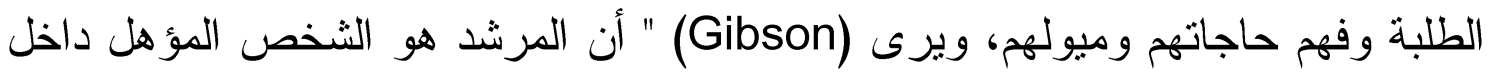
المدرسة الذي نم إعداده لتقديم الإرشاد الفردي و الإرشاد الجمعي للطــلاب و المدرســين و أولياء الأمور" (Gibson, 1983, P284). فالمرشد التربوي فادر على التعامل مع المسترشدين وعلى استيعاب مشاكلهم وفهم الصعوبات التي تمر بهم و انفعالاتهم وأزماتهم وهو القادر على التخطيط للبر امج الإرشادية

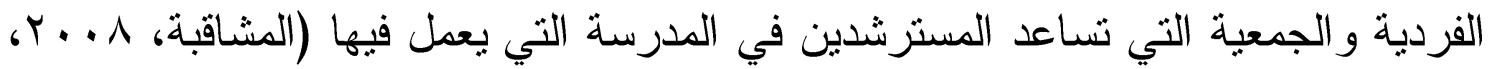

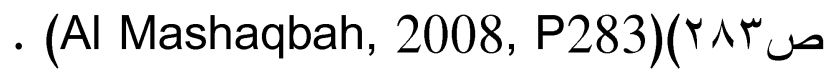
رابعاً : المههام الاساسبة للمرشد التربوي القيام بعملية الإرشاد الجمعي و الفردي لمساعدة الطلبة الذين يعانون مــن مشــكلات نفسية و اجنماعية وتربوية. •القيام بعطية الإرشاد الوقائي وذلك عن طريق المحاضر ات التي تدعم مــن خلالهــــا السلوكيات المر غوبة و التمسك بالقيم الأخلاقية.

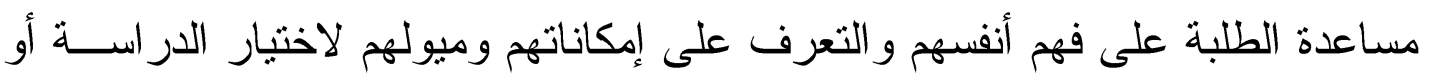
المهنة المناسبة لقدر اتهم.

هنابعة المسترشدين مهما كانت مشكلاتهم وتقييم التحسن الذي يطر أ عليها. يقوم بإحالة المسترشدين الذين يصعب التعامل مع حالاتهم الى مختصين في الخدمـــة

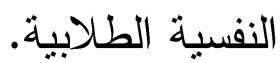

• التعاون مع إدارة المدرسة فيما يتعلق بملفات الطلاب من الناحية التنظيمية. تسجيل المعلومات اللازمة عن كل الطلبة في السجلات المعدة من الوزارة.

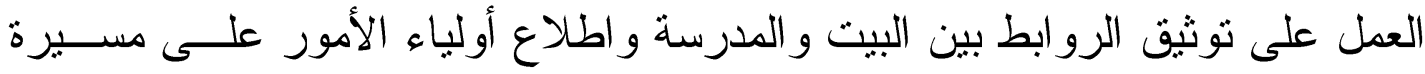
أبنائهم الدر اسية و الاجتماعية و السلوكية داخل المدرسة.

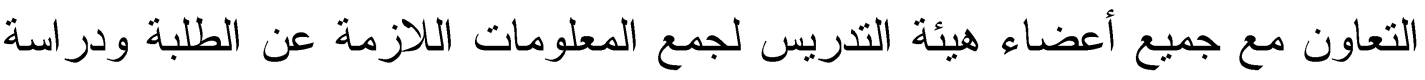

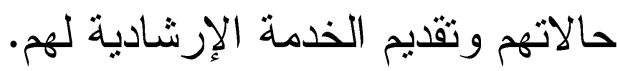


رعاية الطلبة المتفوقين دراسياً و العمل على تتمبة مو اهبهر ، ورعاية الطلبة المتأخرين

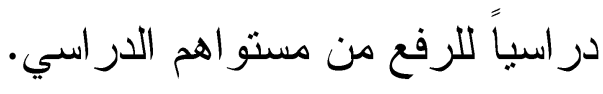

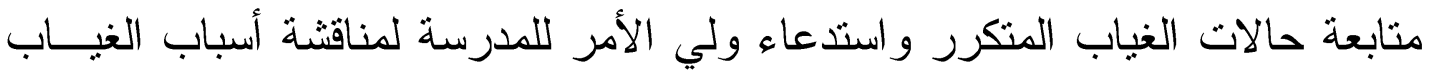
وخطورنه على المستوى الدر اسي للطالب. رعاية الفروق الفردية بين الطلبة في الحاجات و القدر ات و الاستعدادات.

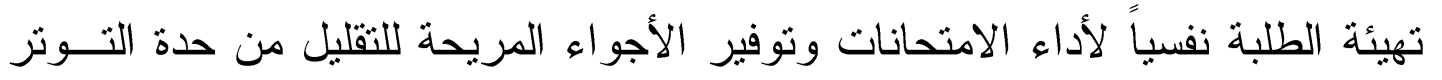
و القلق و الخوف المصاحبة للامتحان.

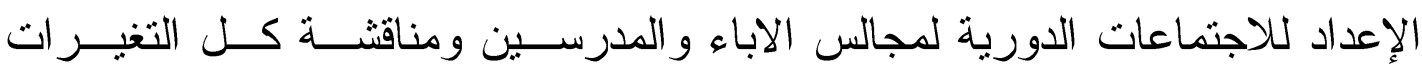

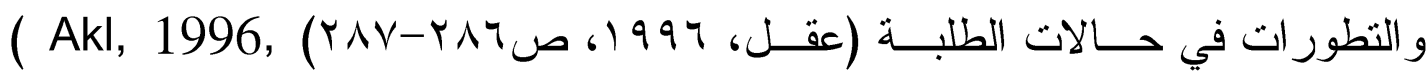
.P286-287)

دراستات سابقة أولاًا : دراسة بندرلي (19vV) (تحليل للفعاليات التي يقوم بها عمال التوجيه في المدارس الابتدائية))

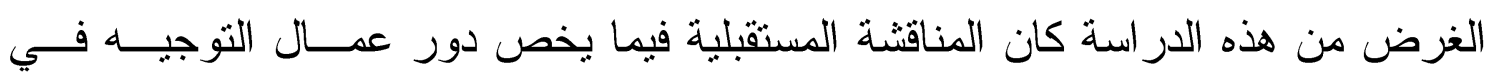

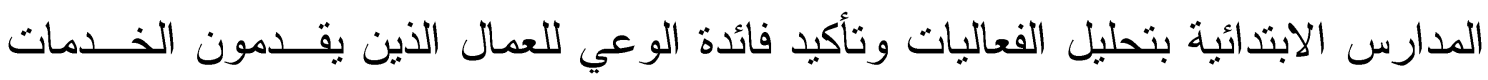
الإرشادية في المدارس الابتدائية.

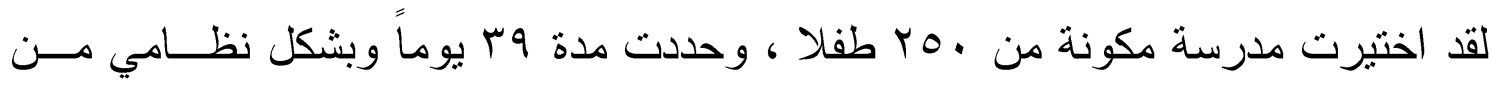

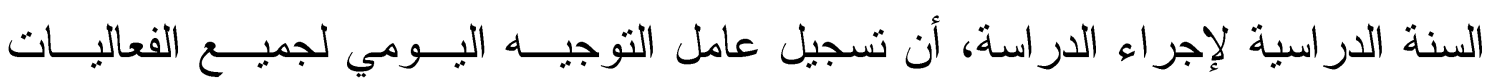

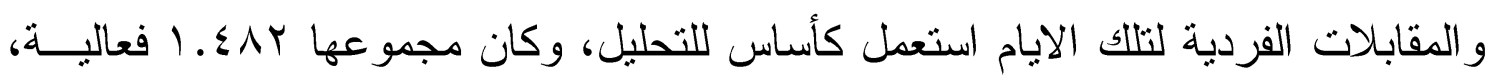

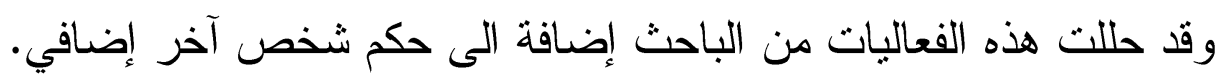

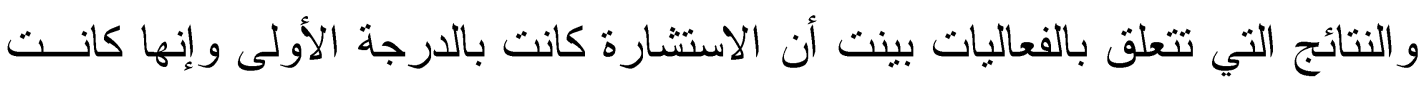

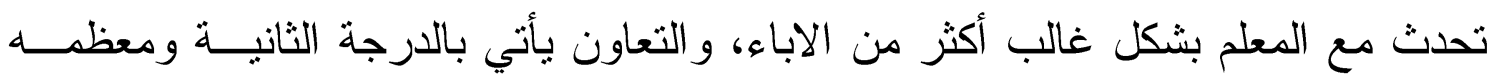

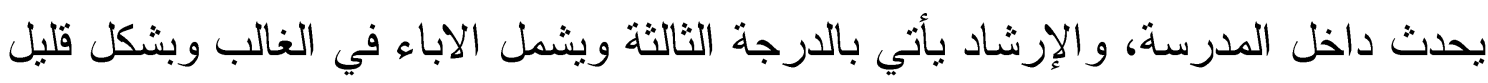

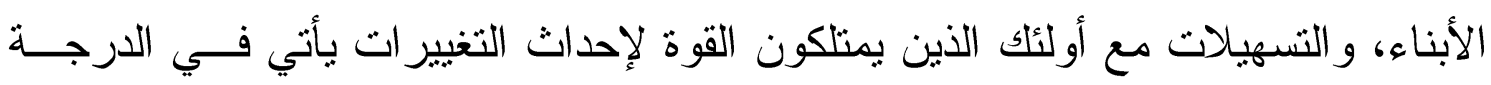
الر ابعة، وملاحظة الأطفال اثثاء اللعب يأني اخيراً. و نتير نتائج الدر اسة ايضاً الى أن: • أكثر من نصف الفعاليات سلطت على التلاميذ بشكل انفر ادي. 
نصف فعاليات المرشد كانت تحدث في مكتبه.

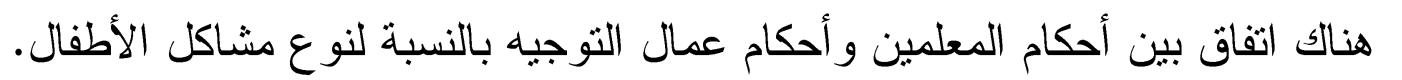

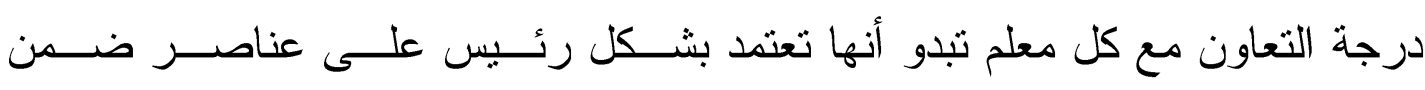
اختصاص المعلم.

وللتأكيد على فائدة خدمات الإرشاد فإن ردود الفعل كانت على الارجح ايجابية من الــذين

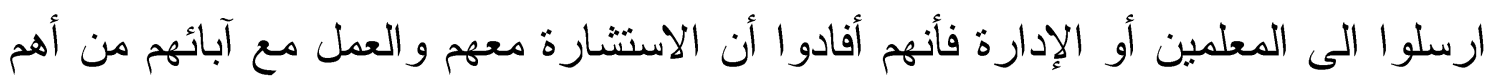
الخدمات التي يقدمها المرشد. ثاتباً : دراسة القبسي (19v^) (تحليل عمل معلمة رياض الأطفال في بغداد)(الديال) استهدفت الدراسة التعرف على الأعمال التي تقوم بها معلمة رياض الأطفال في بغداد خلال يوم در اسي ومدى الاتفاق بين ما نقوم به من أعمال وبين أنموذج أو معيار مقترح.

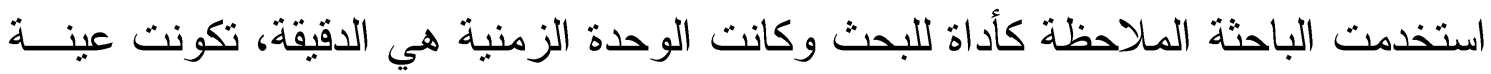

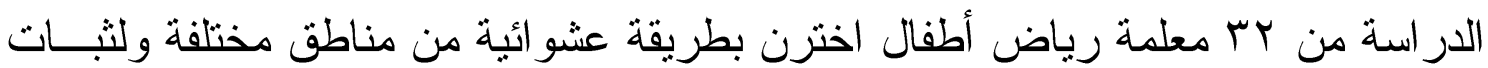

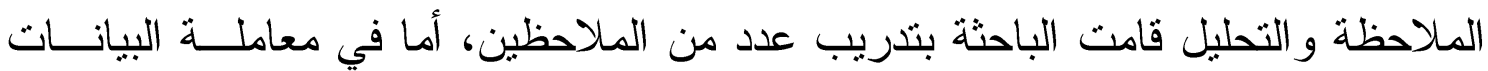
إحصائيا فقد استخدمت الباحثة النسبة المئوية لمعرفة الوقت المصروف فئن في كل مجال من

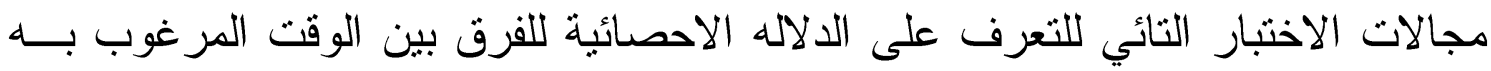
و الوقت المصروف، وكثفت النتائج أن: • مجالات عمل معلمة الرياض ضمن الوقت المصروف ترنتبت حسب أهمينهــا الــى:

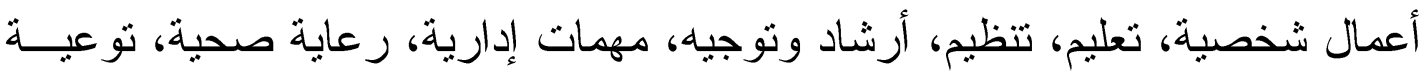
وطنية و اجتماعية. كان هنالك هدر مقداره • ــ دقيقة بين معدل الوقت المصروف و الوقت المطلوب.

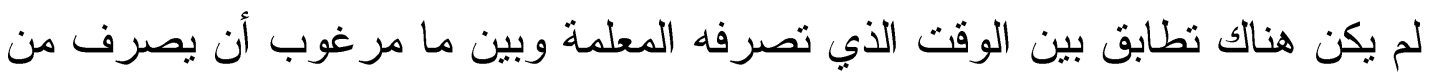
وقت في أي مجال من المجالات السبعة.

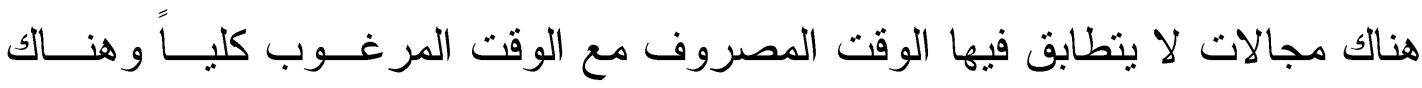
مجالات يكون النطابق جزئياً.

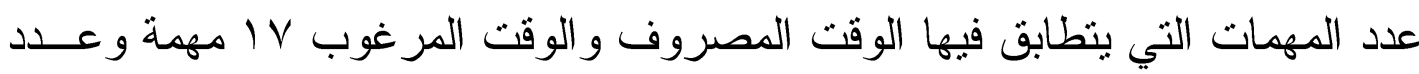
المهمات غير المتطابقة ب ب مهمة. 
توزعت المهمات غير المنطابقة الى مجموعتين: الاولى لصالح الوقــــ المصـروف

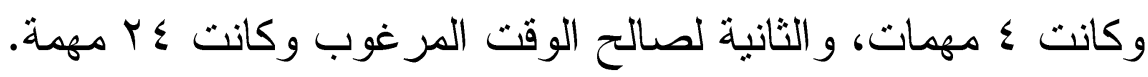
منهج البحث وإجراء(ته

أولاً : منهج البحث

المنهج المستخدم في البحث الحالي هو تحليل العمل وهو من الدراسات الوصــفية التي تهدف الى وصف المهام و المسؤوليات المرنبطة بعمل أو وظيفة نعليمية، وقد بين فان

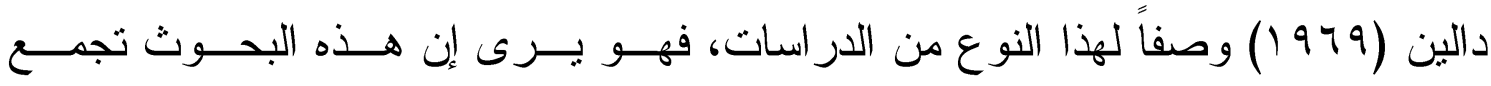

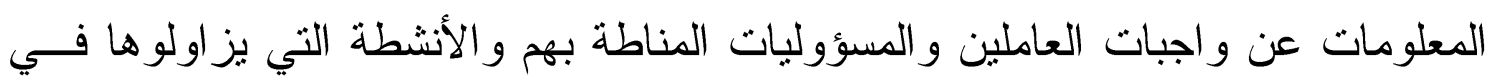

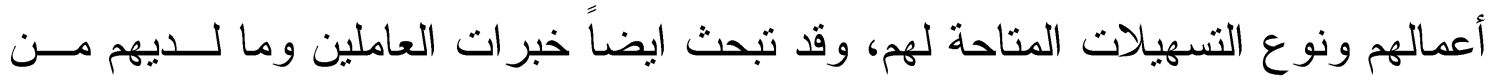

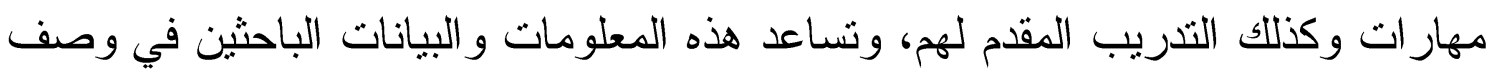

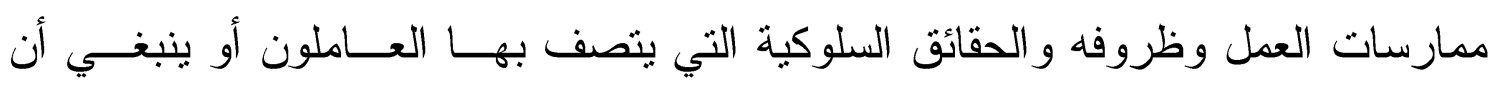

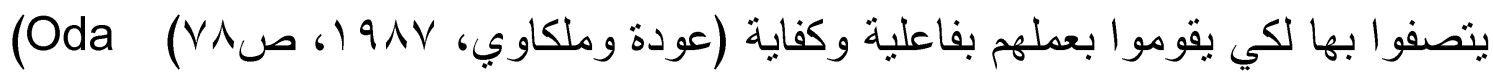
\& Malkawi, 1987, P78) وفي هذا البحث ستعمد الباحثة إلى أن نوثق ما يقوم به المرشــدون مــن خــلد

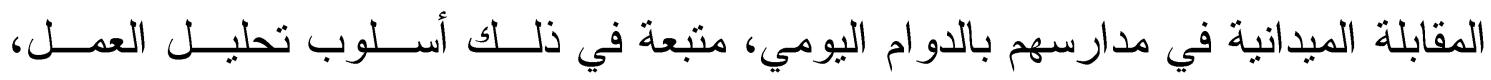

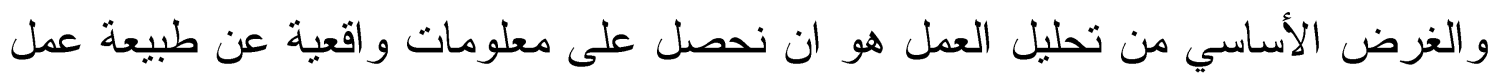

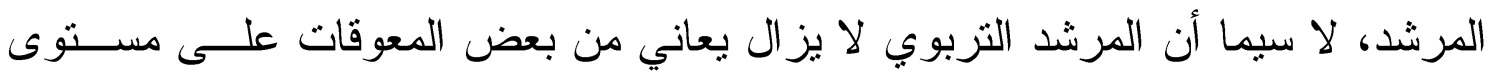

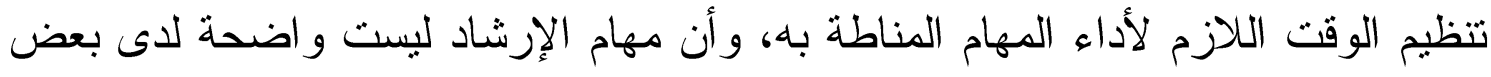
المدر اءو أعضاء هيئة التدريس.

\section{ثانباً : مجتمع البحث}

تحديد مجتمع البحث هو الإطار المرجعي للباحث في اختبار عينة البحث، ويكون

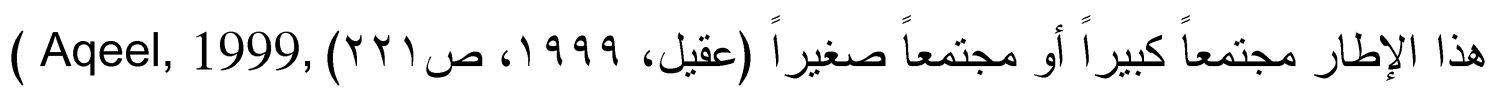

وقد تحدد مجتمع البحث الحالي بالمرشدين التربويين (الذكور و الاناث) العـاملين في مديريات النربية لجانب الكرخ في مدينة بغداد (الكرخ الاولى ، الكرخ الثانية ، الكرخ

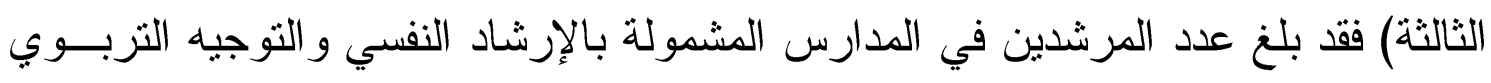




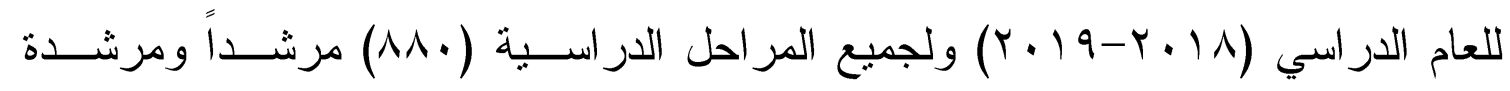
موزعين على المديريات الثلاث، كما في الجدول (1).

جدول (1)

\begin{tabular}{|c|c|c|c|c|c|c|}
\hline النسبة المئوية & المجموع & النسبة المئوية & الاناث & النسبة المئوية & الأكور & المديريات العامة للتربية \\
\hline$\%$ r. & 189 & $\%$ rr & IrV & $\% \backslash \wedge$ & or & الكرخ الاولى \\
\hline$\%$ \% & M & $\%$ \% & rro & $\%$ r & 91 & الكرخ الثانية \\
\hline$\% \leq \varepsilon$ & r^o & $\% \varepsilon$. & rrv & $\% 01$ & $1 \leqslant 1$ & الكرخ الثالثة \\
\hline$\% 1 \ldots$ & $\wedge \wedge$. & $\%$ \% & $0 \wedge 9$ & $\% r r$ & Yq1 & المجموع \\
\hline
\end{tabular}

ثالثاً : عينة البحث

العينة هي جزء من المجتمع، وتتدرس الظاهرة عليهم من خلال المعلومات عـن

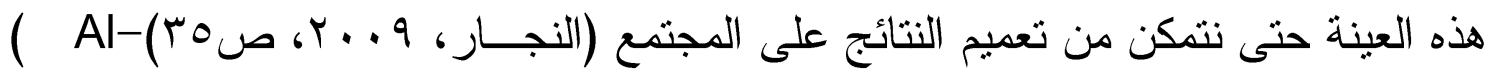
Najjar, 2009, P35) كلما كانت عينة البحث ممثله للمجتمع الأصلي كان تعميم نتائج البحث على المجتمع أدق

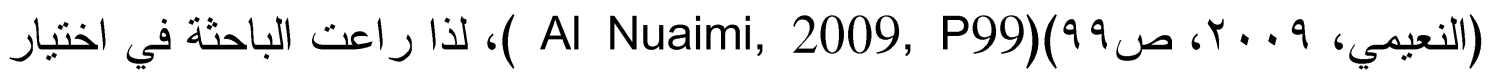
عينة البحث أن تكون ممثله لكل مجتمع المرشدين التزبويين، و اعتمدت علــى الطريقــة

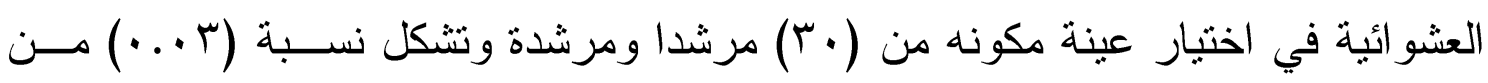
المجتمع الكلي بواقع ( . (1) من كل مديرية.

رابعاً : أداة البحث

لتحقيق هدف البحث (( تحليل عمل المرشد التربوي في المدارس الثانوية )) يجب معرفة وتتظيم الاعمال و المهام التي يقوم بها المرشد التزبوي ليوم در اسي كامل. وللحصول على فكرة و اقعية عن طبيعة العمل زارت الباحثة المرشدين التربويين في مدارسهم ومالاحظة الاعمال التي يؤدوها، وقد أعدت الباحثة بطاقــة الملاحظــة فــي ضوء توصيف عمل المرشد ثبعاً الى : ا . خطة تتظيم عمل المرشد التربوي كأساس لتصنيف الملاحظات الموثقة. r. الأدبيات و الدراسات السابقة المختصة بعمل المرشد التربوي. 
ولكون الباحثة تعمل في مجال الإرشاد النزبوي و النفسي ولديها خبره في العمل وضــعت

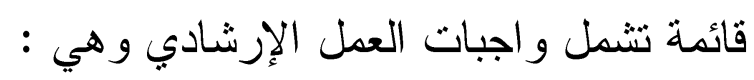

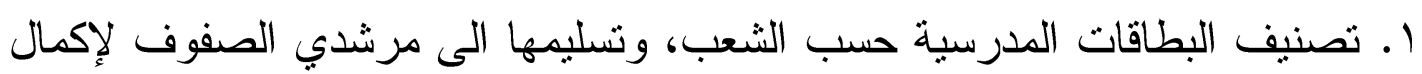
المعلومات الخاصة بالطلبة و الأشر اف على عمل المرشدين بالبطاقة.

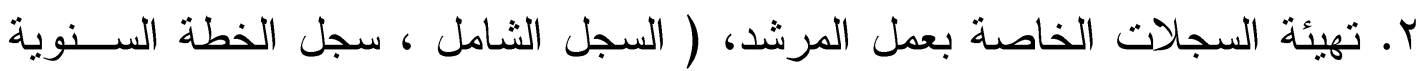

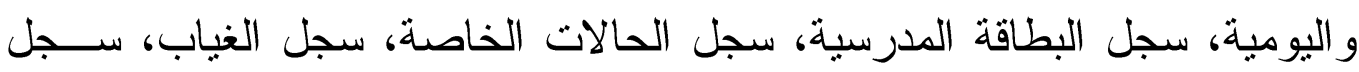

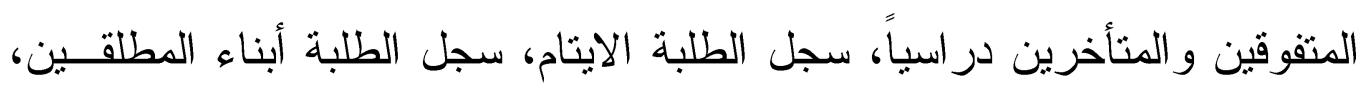
سجل الامر اض المزمنة، سجل الإرشاد الجمعي). r. عقد اجنماعات الدورية مع (مديرة المدرسة، الهيئة التدريسية، أولباء الامور). ع. المشاركة باللجان (لجنة الاحتفالات المدرسية، لجنة السفرات، لجنة الامتحانات). 0. منابعة الطلبة الذين يعانون من مشكلات: نفسية و أخلاقية و صحية. 7. أرشاد الطلبة الذين يقومون بمشكلات يومية :

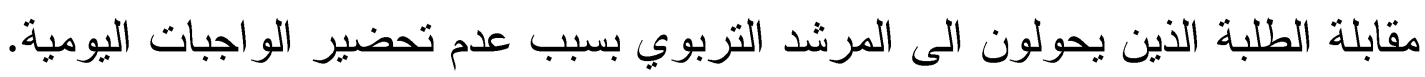
هقابلة الطلبة الذين يحولون الى المرشد التربوي بسبب الغش في الانتحانات.

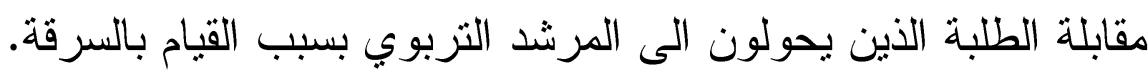
مقابلة الطلبة المخالفين للزي المدرسي.

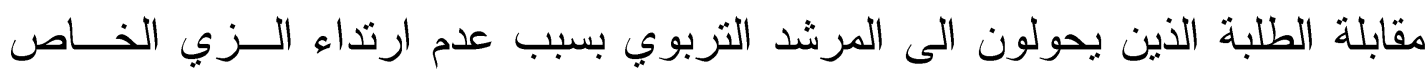
بدرس الرياضة. مقابلة الطلبة الذين لديهم مشاكل مع أعضاء الهيئة التدريسية. هقابلة الطلبة المنمردين على نظام المدرسة. • مقابلة الطلبة الذين يعانون من ضعف الحالة الاقتصادية. هقابلة الطلبة الذين يرغبون بترك المدرسة. • مقابلة الطلبة الذين بعانون من تدني مسنو اهم الدر اسي.

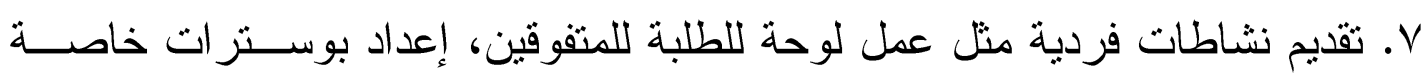
بالإرشاد و غير ها.و الجدو لان (Y) و (r) يوضحان ذلك. لكن. 


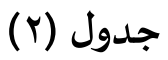

عينة المدارس التي شملها البحث في مديريات تربية بغداد الكرخ وموقعها وعدد الطلبة

\begin{tabular}{|c|c|c|c|c|c|}
\hline المديرية & عدد الطلبة & الموقع & الجنس & اسم المدرسة & $ت$ \\
\hline تربية الكرخ الأولى & $\wedge .$. & الغز الية - شار ع البدالة & 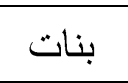 & ث.أم سلمة & 1 \\
\hline تربية الكرخ الأولى & $v_{\cdots}$. & الغز الية - شار ع مدير الأمن & بنات بن & ث. الأنفال & $r$ \\
\hline تربية الكرخ الأولى & $\mathrm{V} \cdot$. & الغزالية - شار ع مدير الأمن & بنين & م. اليمن & $r$ \\
\hline |نربية الكرخ الأولى & $1 \ldots$ & الغز الية- شارع الرئاسة & بنين & م. الدصطفى & $\varepsilon$ \\
\hline تزبية الكرخ الأولى & 10. & الخضر اء & بنين & ع. الخضر اء & 0 \\
\hline تربية الكرخ الأولى & $1 \ldots$ & العامرية & بنين & ع. العامرية & 7 \\
\hline ثزبية الكرخ الأولى & $\varepsilon \ldots$ & حي الجامعة & بنين & م. العراق الجديد & V \\
\hline تربية الكرخ الاولى & $7 . V$ & حي الجامعة & 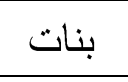 & ع. الخضر اء & $\lambda$ \\
\hline تربية الكرخ الاولى & 7. & حي الجامعة & بنات & م. الأمين & 9 \\
\hline تربية الكرخ الاولى & $\varepsilon 0$. & حي الجامعة & بنات & ع. الفاروق & 1. \\
\hline تربية الكرخ الثانية & $\varepsilon \ldots$ & حي العامل & بنات & ث. هاله بنت خويلد & 11 \\
\hline تربية الكرخ الثانية & rv. & الثرطة الخامسة & بنات & ع. أبابيل & ir \\
\hline تربية الكر خ الثانية & rt. & البياع & بنين & م. ابن الهيثم & 14 \\
\hline تربية الكرخ الثانية & $\varepsilon \varepsilon$. & البياع & بنين & ع. الفار ابي & $1 \varepsilon$ \\
\hline تربية الكرخ الثانية & $r v$. & البياع & بنين & م. المعتصم & 10 \\
\hline تربية الكرخ الثانية & $r \leqslant r$ & حي الجهاد & بنين & ع. حبيب بن مظاهر الاسدي & 17 \\
\hline تربية الكرخ الثانية & $\varepsilon \ldots$ & حي الجهاد & بنات & ع. النهار & iv \\
\hline تربية الكرخ الثانية & ro. & حي الجهاد - تبوك & بنات & ث. وهران & 11 \\
\hline تربية الكرخ الثانية & or. & حي الجهاد - السلام & بنات بن & م. المنهل & 19 \\
\hline تربية الكرخ الثانية & ro. & السيدية & بنين & م. عقبه بن نافع & $r$. \\
\hline تربية الكرخ الثالثة & 0.7 & رحمانية الثعلة & بنات & ع. الفوز & $r$ \\
\hline تربية الكرخ الثالثة & 7. & الحرية & بنين & م. الفرقدين & rr \\
\hline تربية الكرخ الثالثة & $\wedge \ldots$ & الحرية & بنين & م. النحريز & rT \\
\hline تربية الكر خ الثالثة & 91. & الحرية & بنات & م. المحمرة & $r \varepsilon$ \\
\hline تربية الكرخ الثالثة & $\wedge \ldots$ & الحرية & بنات & ع. جريز & ro \\
\hline تربية الكرخ الثالثة & $r \ldots$ & العدل & بنين & ع. الزور اء & r4 \\
\hline تربية الكرخ الثالثة & 7. & العدل & بنات ب & ث. الخلود & rV \\
\hline
\end{tabular}




\begin{tabular}{|c|c|c|c|c|c|}
\hline تربية الكرخ الثالثة & 00. & الكاظمية & بنين & م. دجلة & rᄉ \\
\hline تربية الكرخ الثالثة & $\leqslant 0$. & الكاظمية & بنات & م. الز هر اء & rq \\
\hline نزبية الكرخ الثالثة & $\varepsilon \ldots$ & الكاظمبة & بنات & ع. رقية بنت الحسين & r. \\
\hline
\end{tabular}

جدول (r)

اسم المرشد وتاريخ ووقت الزيارة

\begin{tabular}{|c|c|c|c|c|c|}
\hline الدقيقة & فتزة المشاهدة & تاريخ الزيارة & اسم المرشد & اسم المدرسة & ت ت ت \\
\hline ir. & 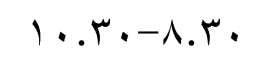 & $r \cdot 11 / 1 \cdot / 9$ & رائدة فاضل يوسف & ث.أم سلمة & 1 \\
\hline $1 \cdots$ & 1 K.r.-1..0. & $r \cdot 11 / 1 \cdot / 9$ & يُسر قصي عبدالمنعم & ث. الأنفال & r \\
\hline 9. & $1 \cdot . r \cdot-9 .$. & $r \cdot 11 / 1 \cdot / 1$. & وسام محمد داود & م. اليمن & $r$ \\
\hline 110 & $\mid r . \varepsilon \cdot-1 \cdot . \leqslant 0$ & $r \cdot \mid \wedge / 1 \cdot / 1$. & محمد سليم حمادي & م. المصطفى & $\varepsilon$ \\
\hline iro & $11 \ldots-1 . \leqslant 0$ & $r \cdot 11 / 1 \cdot / 11$ & محمد علي احمد & ع. الخضر اء & 0 \\
\hline$i r$. & Ir.r.-1. r. & $r \cdot 11 / 1 \cdot / 11$ & يوسف مستوفي محمد & ع. العامرية & 7 \\
\hline 1.0 & $1.10-\Lambda . r$. & $r \cdot 11 / 1 . / 1 \mathrm{~V}$ & طارق عصام مهدي & م. العر اق الجديد & v \\
\hline$i r$. & Ir.r.-1..r. & $r \cdot 11 / 1 \cdot / \mathrm{V}$ & علياء حلمي عبدالكريم & ع. الخضر اء & $\wedge$ \\
\hline 1.0 & $1 . .50-9 . \ldots$ & $r \cdot 11 / 1 \cdot / 11$ & ميادة علي حسين & م. الأمين & 9 \\
\hline 7. & $\mid r . r \cdot-11 . r$. & $r \cdot 11 / 1 \cdot / 11$ & غيداء طارق احمد & ع. الفاروق & 1. \\
\hline 9. & q.r.-1... & $r \cdot 11 / 1 \cdot / 11$ & سليمة شخير فالح & ث. هاله بنت خويلد & 11 \\
\hline 11. & $1 r_{.0-1.10}$ & $r \cdot 11 / 1 \cdot / r$ & شروق لطيف جو اد & ع. أبابيل & ir \\
\hline 9. & $1 \cdots-\Lambda . \mu$ & $r \cdot 11 / 1 \cdot / r \leq$ & سيف محي عبدالله & م. ابن الهيثم & r \\
\hline 9. & $1, \ldots-1 \cdot . r$. & $r \cdot 11 / 1 \cdot / r \varepsilon$ & حسام اكرم حسن & ع. الفار ابي & $1 \leq$ \\
\hline M. & $11.1 .-9 .$. & $r \cdot 11 / 1 . / r_{0}$ & حيدر محسن عودة & م. المعتصم & 10 \\
\hline 9. & $1 \cdot \ldots-\Lambda . r$ & $r \cdot \mid \Lambda / 1 \cdot / r$. & عامر محمد عبدالرضـا & ع. حبيب بن مظاهر الاسدي & 17 \\
\hline Ir. & Ir.r.-I. r. & $r \cdot 1 \wedge / 1 \cdot / r$. & يسار بكر فاضل & ع. النهار & iv \\
\hline$V \cdot$ & 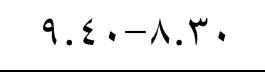 & $r \cdot \mid N / \mu \cdot / r_{1}$ & ارتقاء خالد محمد & ث. وهران & 11 \\
\hline $1 r$. & $1, \ldots-1 \ldots$ & $r \cdot|\Lambda / 1 \cdot / r|$ & حور اء عبود عباس & م. المنهل & 19 \\
\hline Ir. & $11 . r .-9 . r$. & $r \cdot 11 / 11 / 7$ & رياض حمبد جوهر & م. عقبة بن نافع & $r \cdot$ \\
\hline 10. & $11.10-1 . \leqslant 0$ & $r \cdot 11 / 11 / V$ & أسماء سرحان عودة & ع. الفوز & r) \\
\hline 9. & $1 . \ldots-\Lambda . r$ & $r \cdot 11 / 11 / 1$ & احمد عبد كاطع & م. الفرقدين & rr \\
\hline $1 \cdots$ & $1, \ldots-1 \cdot . r$. & $r \cdot 11 / 11 / \wedge$ & حيدر جابر زاهر & م. التحرير & r \\
\hline
\end{tabular}




\begin{tabular}{|c|c|c|c|c|c|}
\hline$\wedge$ & l. r. $-9 .$. & $r \cdot 11 / 11 / 1 r$ & ر ائده جعفر رشبد & م. المحمرة & $r \leq$ \\
\hline 11. & Ir.ro-1. ro & $r \cdot 11 / 11 / 1 r$ & وصسال عبد الكريم & ع. جرير & ro \\
\hline 9. & l. r. - . . . & $r \cdot \mid 1 / 11 / 1 \varepsilon$ & علي عبدالرزق عباس & ع. الزور اء & ry \\
\hline 1.0 & $\mid r . \leqslant 0-11 \ldots$ & $r \cdot \mid \wedge / 1 / / \varepsilon$ & معاني حمود سعود & ث. الخلود & rV \\
\hline 7. & $1 \ldots-9 . \ldots$ & $r \cdot 11 / 11 / 10$ & رعد محمد جاسم & م. دجلة & $r \wedge$ \\
\hline vo & $11 . r \cdot-1 \cdot .10$ & $r \cdot 11 / 11 / 10$ & أزهار عدنان & م. الزهر اء & rq \\
\hline 7. & $1 \ldots-1 r_{\ldots}$. & $r \cdot 11 / 11 / 10$ & شلير عبد الله & ع. رقية بنت الحسين & $r$. \\
\hline
\end{tabular}

خامساً : تطبيق الأداة

طبقت الأداة على عينة البحث عن طريق المقابلة الفردية، وسجلت الملاحظــات باستخدام الورقة و القلم لنسجيل كل عمل يقوم بـ المرشد وحساب الزمن له، ووضـع أمسـام كل عمل يقوم به المرشد رقم المجال الموجود في الخطة ثم جمعت الاعمـــال المنشــابهة

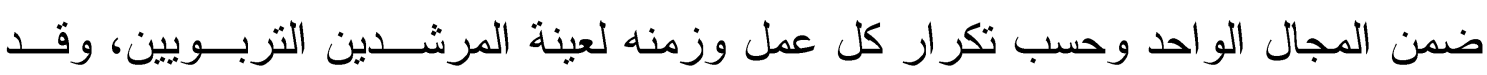

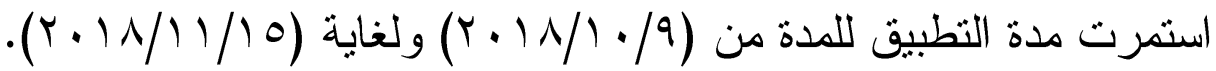

\section{عرض النتائج ومناقشتها}

من تحليل الملاحظات و البيانات لــ ( • ب) مرشداً ومرشدة ظهر أن الوقت الذي

يبذله المرشدون في العمل يبلغ ( • 1 - • 7) دقيقة، و الجدول (ع) يوضح ذلك. ولقد توزع الوقت الذي بذله المرشدون في العمل على مجالات عدة هي :

ا ـ مجال البطاقة المدرسية.

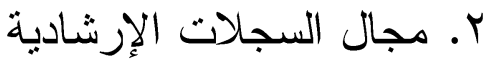

r. مجال الاجتماعات

ع. ـ مجال الإرشاد الجمعي

๑. مجال الحالات

7. مجال المشكلات

V. مجال الانشطة اللاصفية 


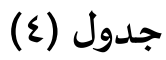

المجالات التي توزع عليها عمل المرشدين وتكرارها والزمن المبذول والمعدل

\begin{tabular}{|c|c|c|c|c|}
\hline النسبه & المعدل & الزمن & التكر ار & المجالات \\
\hline$\% 19$ & 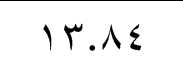 & r. & r & مجال المشكلات اليومية \\
\hline$\% \backslash V$ & $1 V . .0$ & TrE & 19 & مجال دروس الإرشاد الجمعي \\
\hline$\% \backslash \vee$ & r. $1 . \varepsilon$ & rrl & 10 & مجال السجلات الإرشادية \\
\hline$\% 1 r$ & I 纟.V. & ro. & iv & مجال الحالات الخاصة \\
\hline$\% 1 r$ & TI.TV & $r r \varepsilon$ & 11 & مجال البطاقة المدرسية \\
\hline$\% 1 r$ & 9.rvo & rro & $r \varepsilon$ & مجال الاجنماعات \\
\hline$\% 1$ & 9 & 11. & $r$. & مجال الانشطة اللاصفية \\
\hline$\% 1 \ldots$ & 1.7.7. & $119 \varepsilon$ & Tr & \\
\hline
\end{tabular}

يتضح من الجدول اعلاه أن مجال المشكلات اليومية احتل المرنبة الأولى من وقت دابت

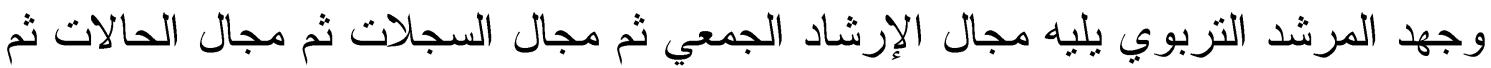

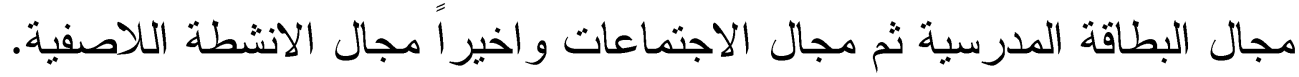

\section{أولاً: مجال المشكلات اليومية}

احتل هذا المجال المرتبة الأولى من وقت وجهد المرشد التربوي، فقـــــــتـرق

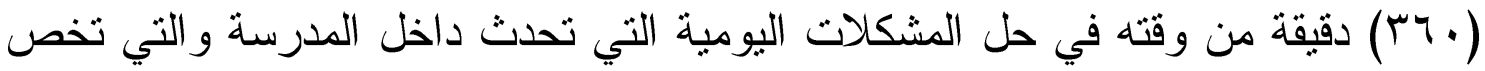
تعامل الطلبة مع بعضهم ومتابعة مستو اهم الدراسي وسلوكهم الاجنماعي داخل المدرســة وكذلك تعامل أعضاء الهيئة التثريسية مع الطلبة.

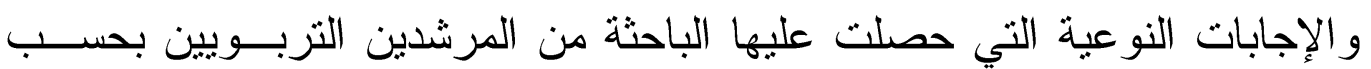

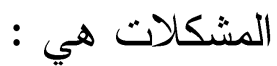
مقابلة طلبة لم يحضروا الو اجبات مقابلة الطلبة الر اسبين

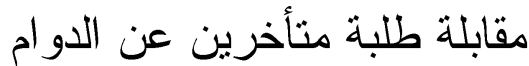
مقابلة طلبة لا يلبسون الزي المدرسي لني مقابلة طلبة يشتكون من أسلوب بعض المدرسين مقابلة طلبة يشتكون من طريقة تدريس بعض المدرسين

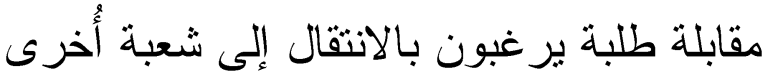


مقابلة طالبة متفوقة ونز غب بنرك المدرسة مقابلة طلبة يسألون عن اكمال النقص في كتبهم المدرسية

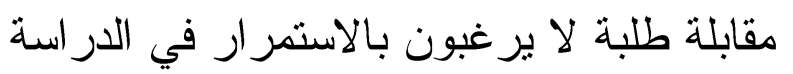

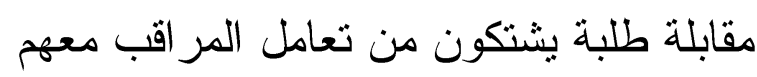

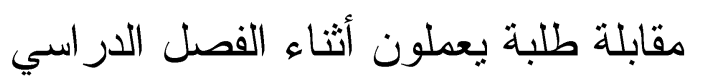
مقابلة طلبة هاربين من المدرسة

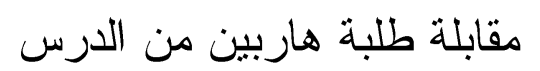

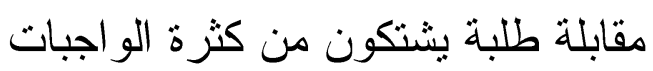

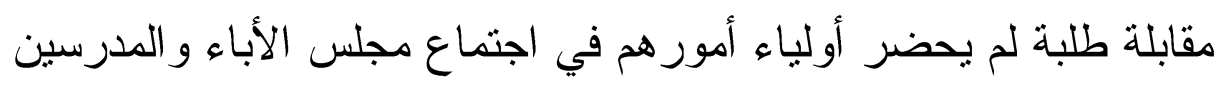

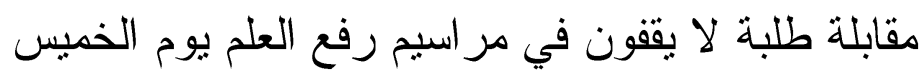

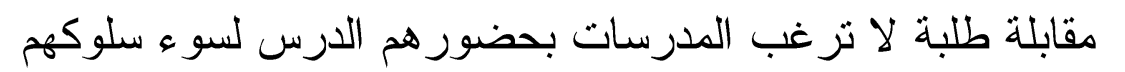
• مقابلة طلبة يردون النفايات على الارض في المدرسة

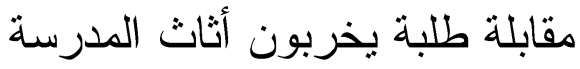

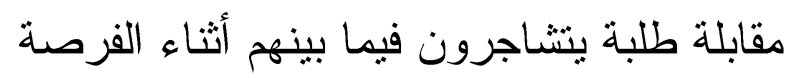
مقابلة طلبة بعانون من ضعف الحالة الاقتصادية

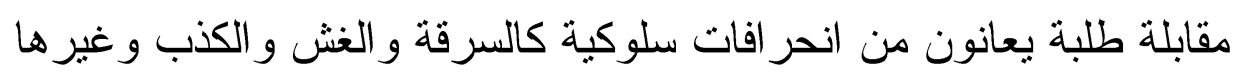
ثانياً: مجال دروس الإرشاد الجمعي

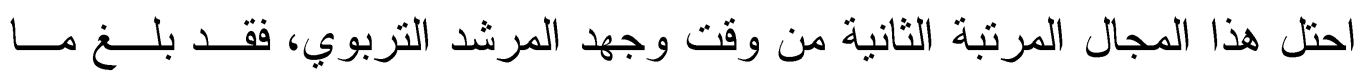

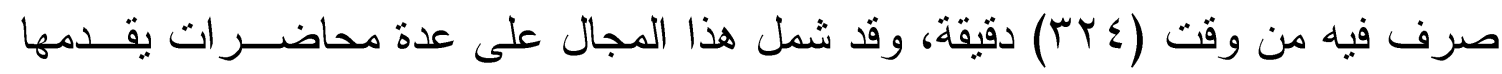

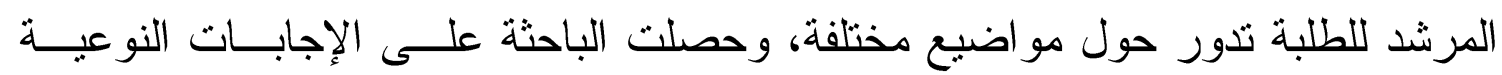

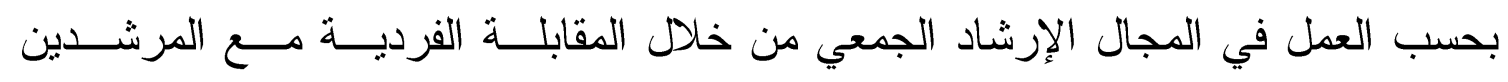

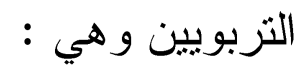
الإرشاد الجمعي للصف الاول للتعريف بالإرشاد وتوضيح أهمية دور المرشـــ فـي المدرسة.

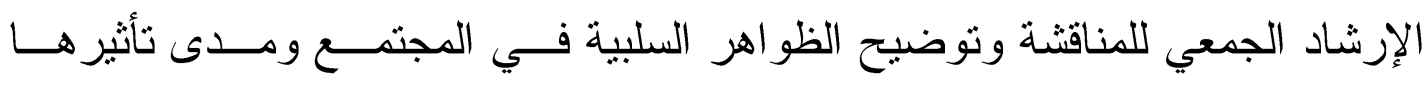
كالتنخين و العنصرية و غير ها. 
الإرشاد الجمعي لتعريف الطلبة بمرحلة المر اهقة و التغير ات الني تحدث فيها.

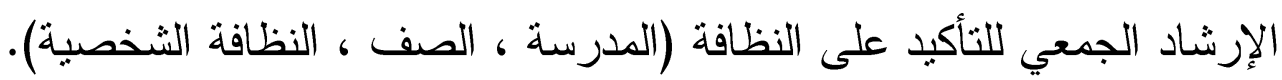

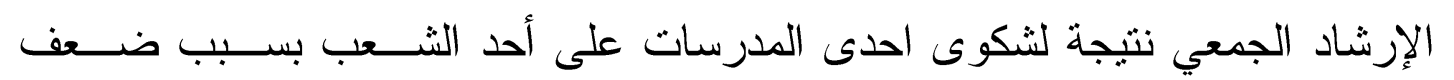

$$
\text { مسنو اهم الدر اسي أو سوء سلوكهم. }
$$

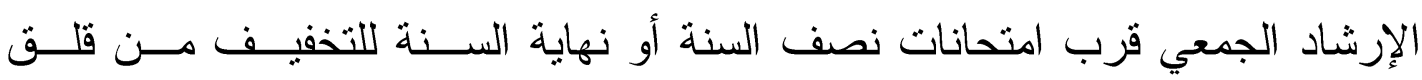

$$
\text { الامتحان. }
$$

•الإرشاد الجمعي للصفوف المنتهية للتأكيد على المستوى العلمي وكيفية اختيار نــوع

$$
\text { الدر اسة المناسبة لكل طالب. }
$$

ثالثاً: مجال السجلات الإرشادية

احتل هذا المجال المرنبة الثالثة من وقت وجهد المرشد الثربوي، فقد بلغ الوقــت

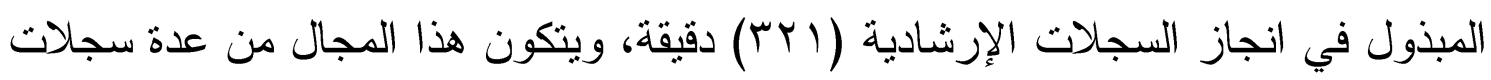
يملؤها المرشد ويستقبد منها في عمله وهي: • سجل الخطة السنوية و اليومية

• مجل البطاقة المدرسية

• - مجل الطلبة الايتام

• سجل الطلبة أبناء المطلقين الابنام

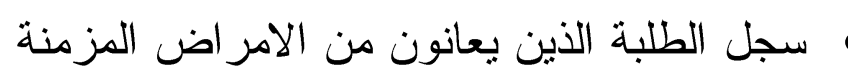

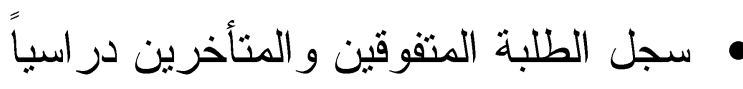

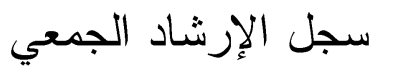

سجل الحالات الخاصة

هجل الغياب للطلبة

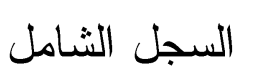

رابعاً: مجال الحالات الخاصة

احتل مجال الحالات المرثبة الر ابعة من وقت وجهد المرشد التربوي، واســتغرق

(Yo. ) دقيقة، وقد اثنتمل على عدة حالات نفسية وصحية وأخلاقية. 


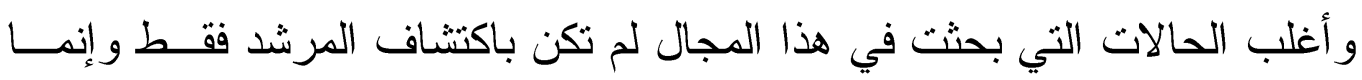
بإحالة من أدارة المدرسة أو من احد أعضاء الهيئة التدريسية، ومن خلال مقابلة المرشدين

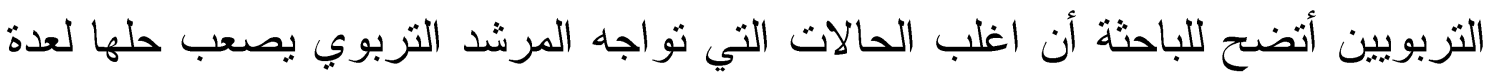

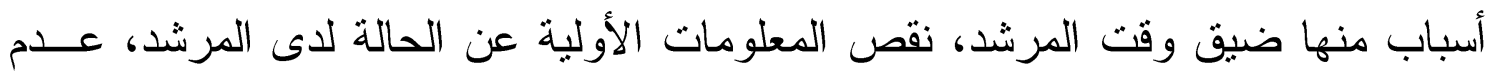

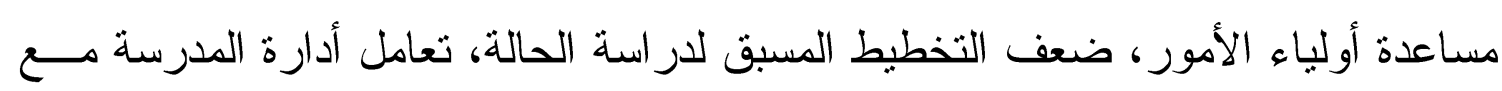
الحالات الأخلاقية بأسلوب إداري أقرب منه الى الأسلوب الإرشادي.

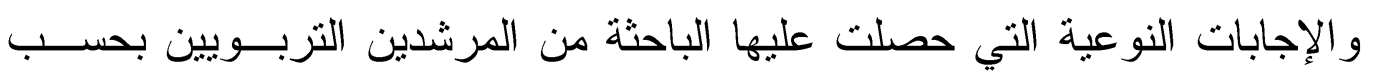

$$
\text { الحالات الواردة في المدارس هي: }
$$

متابعة الطلبة الذين يعاملون زملاءهم بعدو انية.

متابعة الطلبة المتمردين على نظام المدرسة. هنابعة الطلبة الذين يشعرون بالخوف من المدرسة ومن زملائهم.

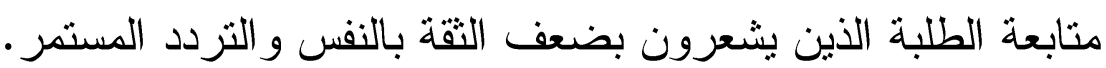
هنابعة الطلبة الذين يشعرون بالوحدة دائماً.

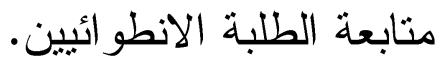
متابعة الطلبة الذين بعانون من أمر اض مزمنة. منابعة الطلبة الذين يمرون بمشكلات عاطفية. متابعة الطلبة الذين بمارسون سلوكيات لا أخلاقية.

\section{خامساً: مجال البطاقة المدرسبة}

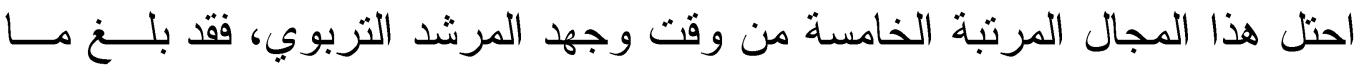

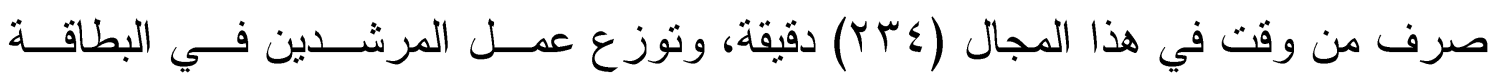

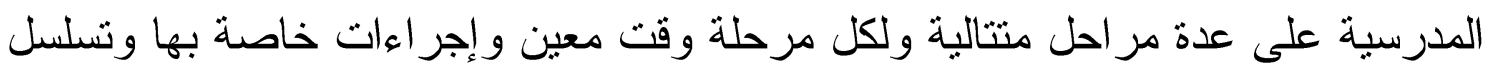

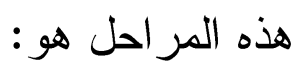
ترحيل البطاقات من مرحلة الى أخرى. • تكملة النو اقص في إعداد البطاقات.

تسليم البطاقات الى مرشدين الصفوف لكتابة المعلومات الخاصة بكل طالب فيها. • استلامها من مرشدين الصفوف و التأكد من طريقة إملائها. 
سـادساً: مجال الاجتماعات

احتل هذا المجال المرنبة السادسة من وقت وجهد المرشد التزبوي، فقد اســتغرق

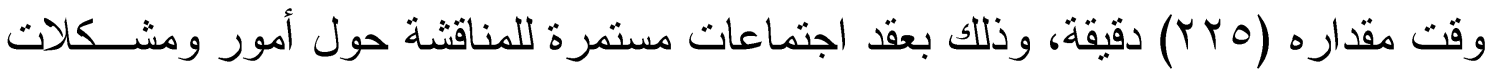

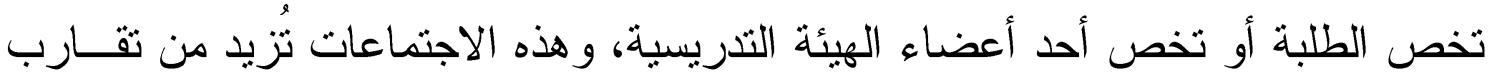

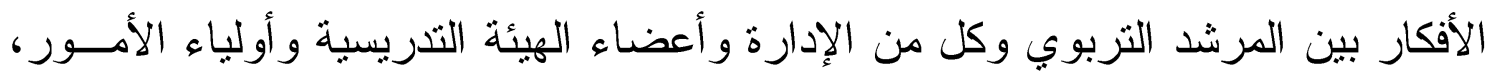

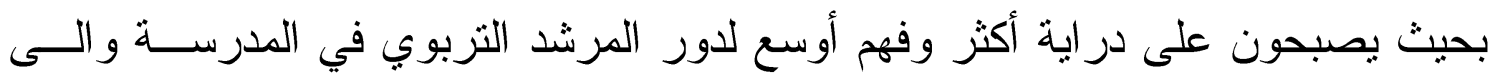

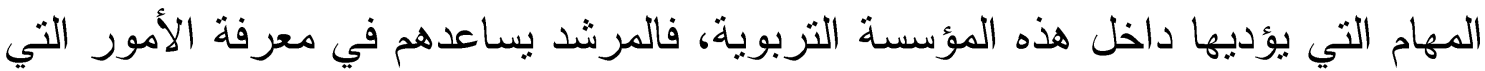
تخص الطلبة وقد يغفلون عنها. وتعقد هذه الاجتماعات مع: مديرة المدرسة

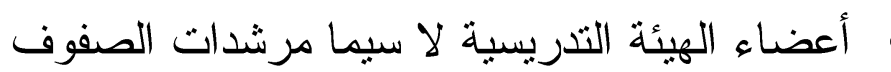
أولياء أمور الطلبة أو أنهاء

\section{سابعاً: مجال الانشطة اللاصفية}

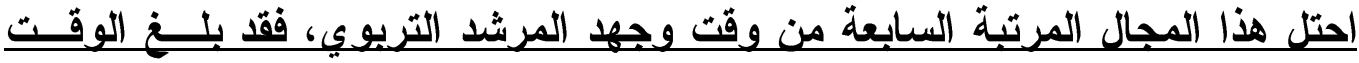

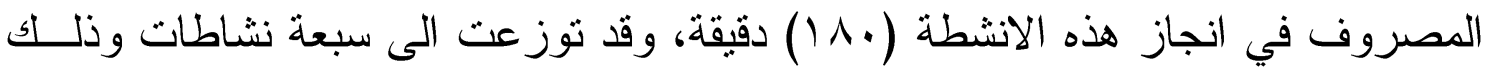
حسب الإجابات النوعية التي حصلت عليها الباحثة من مقابلتها مع المرشدين النزبـــيين وهي : مشاركة المرشد التربوي بالاحتفالات و السفرات. هشاركة المرشد التربوي بالعمل الثعبي لنظافة المدرسة.

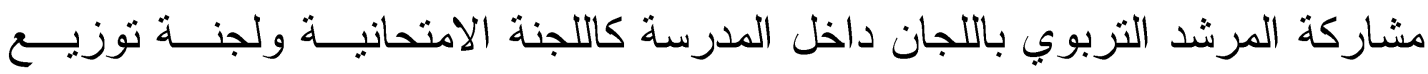

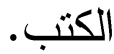
قِيام المرشد التربوب بجولة في ساحة المدرسة لمتابعة الطلبــة وملاحظـــة الظـــو اهر

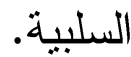
متابعة حانوت المدرسة وصلاحية المو اد الني يوفرها. عمل لوحة للطلبة المتميزين. إعداد بوسنر ات إرشادية. 


\section{الاستنتاجات و التوصيات و المقترحات}

الاستتنتاجات

من خلال تحليل جميع تفاصيل عمل المرشد التربوي اتضحت جملـــة ملاحظـــات

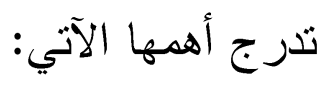

ا. احتلت المشكلات اليومية الجزء الأكبر من وقت المرشد النزبوي داخل المدرسة وذلك

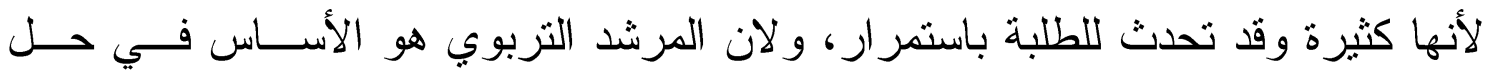
المشكلات التي يمر بها الطلبة على مدار السنة لذلك يلجئون إليه.

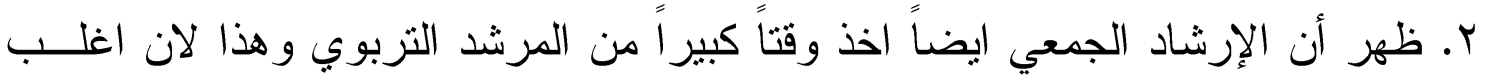

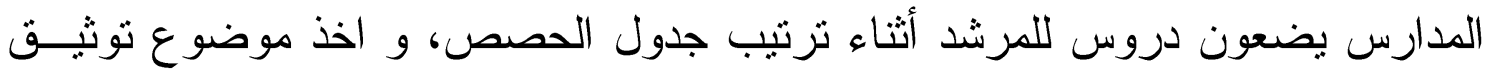

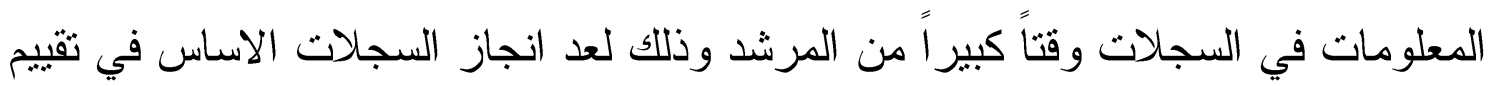
عمله في المدرسة. وينبغي أن نذكر هنا التفاوت الكبير في نوع التوثيق فهناك اجنهـادات

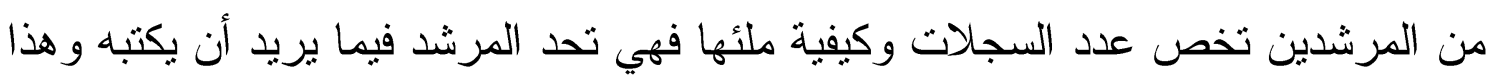
ما يجعل التوثيق عند بعض المرشدين بصل الى حدوده الدنبا.

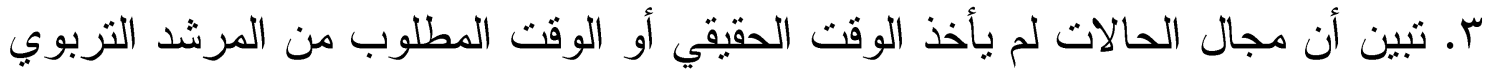

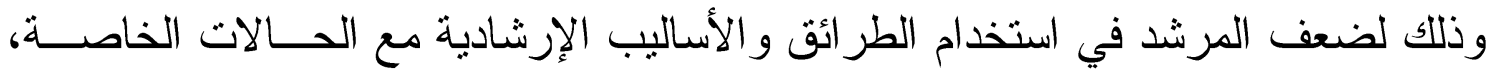

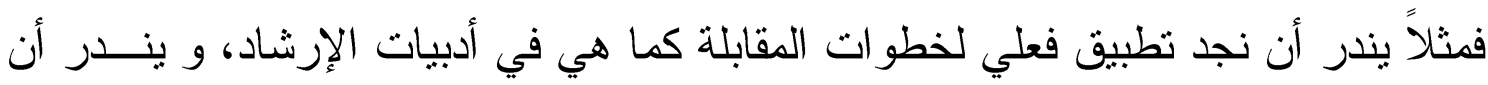
نجد المرشد الذي يعد مسبقاً المعلومات اللازمة في معالجة الحالات الخاصة قبل مقابلتها، بل أن اغلب المرشدين يستخدمون الأساليب التقليدية في معالجة الحالات.

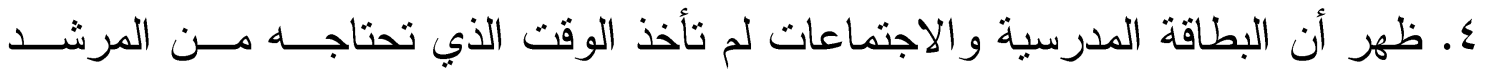

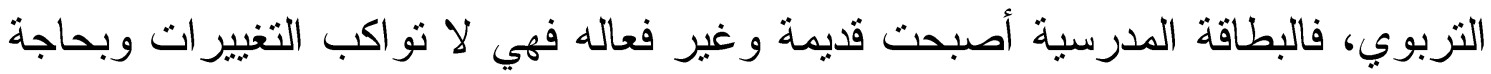

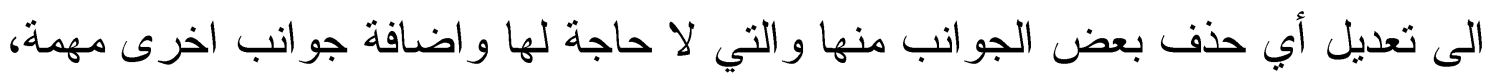
اما الاجنماعات فأنها قليلة لان ضيق الوقت بحد من عقد الاجتماعات.

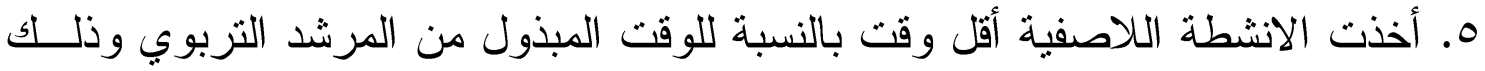
بسبب تعدد المهام الو اقعة على عاتق المرشد و المسؤوليات المناطة به. 
التوصيات

من خلال النتائج والاستنتاجات النهائية توصلت الباحثة الى عدد من التوصـيات ترى أنها ضرورية لنطوير عمل المرشد التزبوي وهي :

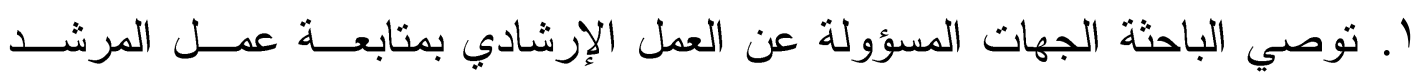

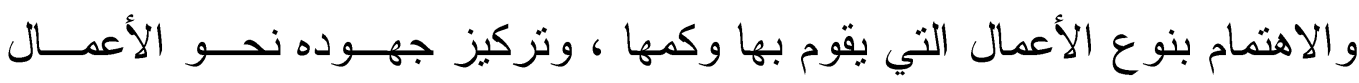

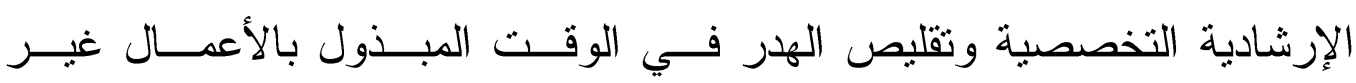
التخصصية.

r. و توصي ايضا الجهات المسؤولة عن العمل الإرشادي السماح لكل مرشد بتوثيق

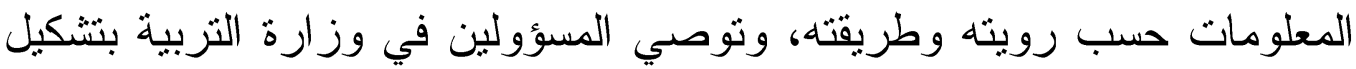
لجنة من الإرشاد لتعديل البطاقة المدرسية بما يناسب التغير ات الحاصلة.

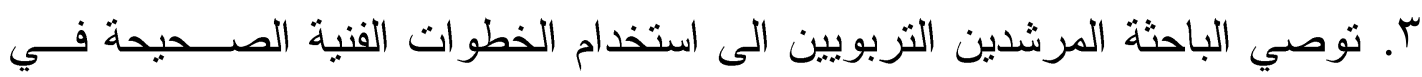
الطرق و الأساليب الإرشادية وخاصة في المقابلة.

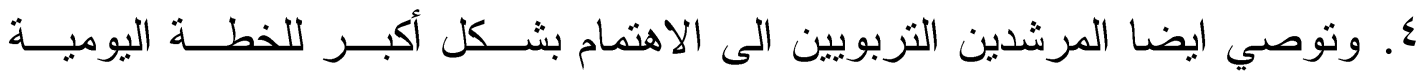
و الإعداد لها مسبقاً وليس لاحقاً أو آنياً.

المقترحات

تقترح الباحثة في ضو ء اجر اءات ونتائج البحث الحالي ما ياتي : 1- اجر اء در اسة لنعرف الصعوبات الني يوجهها المرشد التربوي في عمله الارشادي r-اجر اء در اسة لتحليل بيئة العمل الارشادي في ضو هونطلبات التنمية المستدامة.

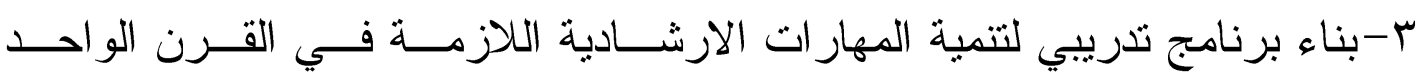

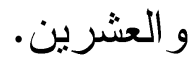




\section{References}

- Ramah, Abbas Ramadan (1986) Difficulties facing educational guidance in the intermediate stage from the point of view of the educational advisors and directors in the center of Baghdad Governorate, Master's thesis (unpublished), University of Baghdad.

- Saleh, Saleh Mahdi (1995) Psychological combustion of educational advisors and its relationship with certain variables, $\mathrm{PhD}$ Dissertation (unpublished), Faculty of Education, University of Mustansiriyah.

- Hayani, Asim Mahmoud Nada (1989) Educational and psychological counseling, Dar Al-Kutub for printing and publishing, Mosul.

- Hamdoon, Ghanem et al. (1975) Analysis of Teacher's work in Baghdad elementary schools, Center for Educational and Psychological research, University of Baghdad.

- Ministry of Education (1988) Guide to Education Advisor, General Directorate of Evaluation and Exams, Directorate of Evaluation and Educational guidance, Baghdad.

- Taher, Hussain Mohammed Ali and Al-Jardi, Mohieddin Yusuf (1986): Psychological and pedagogical guidance between originality and renewal.

- Khatib, Saleh Ahmed (2003) Psychological Counseling at school: Foundations, Theories, applications, University Book House, United Arab Emirates.

- Darraji, Hasan Ali Al-Sayed and Marzouk, Sahib Abed (2012) Psychological counseling and mental health, Noor Al-Hasan Typing Office, Baghdad.

- Al Mashaqbah, Mohammed Ahmed Khaddam (2008) Principles of psychological counseling, curriculum House for printing and publishing, Amman, Jordan.

- Akl, Mahmoud Atta Hussein (1996) Psychological and educational counseling, Dar al Khraji for Printing and Publishing, Riyadh.

- Al-Qaisi, Khawla Abdul Wahab (1978) Analysis of the work of kindergarten teacher in Baghdad, Master's thesis, Faculty of Education, University of Baghdad.

- Oda, Ahmed Suleiman and Malkawi, Fathi Hassan (1987) The Basics of scientific research in education and humanities (its elements and methods 
and statistical analysis of its data), Al Manar Publishing and Distribution library, Department of Education, Yarmouk University.

- Aqeel, Aqeel Hussain (1999) Philosophy of scientific research curricula, madbouly library, Tripoli.

- Al-Najjar, Nabil Juma' Saleh (2009): Statistics in Education and humanities (SPSS programming applications), $1^{\text {st }}$ ed., Dar al-Hamed for printing and publishing, Mu'tah University, Jordan.

- Al Nuaimi, Abbasseya Musa Khalil (2009) Suspicion of communication and its relationship with self-esteem of educational advisors in Baghdad Governorate, Master's Thesis (unpublished), Faculty of Education, University of Mustansiriyah.

Gibson, R (1983) Development and Management of Counseling, Macmillin Co., Inc. Arthur, R (1963).

(المصادر

ردح، عباس رمضان (T1911): الصعوبات التي تواجه الارشــاد التربــوي في المرحلة المتوسطة من وجهة نظر المرشدين التربويين والمــدراء فـي مركـز محافظة بغداد، رسالة ماجستير (غير منشورة)، جامعة بغداد.

صالح، صالح مهدي (990 (1)): الاحتراق النفسي لــى المرشــدين التربــوينين وعلاقته ببعض المتغيرات، أطروحة دكتور اه (غير منشــورة)، كليــة التربيــة، الجامعة المستتصرية.

الحياني، عاصم محمود ندا (919 ( )): الإرشـاد التربــوي والنفســي، دار الكتـبـ للطباعة و النشر ، الموصل. حمدن، غانم و آخرون (9v0): تحليل عمل المعلم في مدارس بغداد الابتدائية، مركز البحوث التربوية و النفسية، جادعة بغداد.

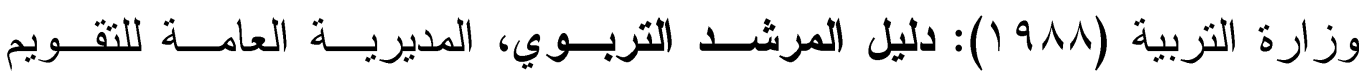
و الامتحانات، مديرية التقويم و التوجيه التزبوب، بغداد. طاهر، حسين محمد علي و الجردي، محي الــدين يوسـف (919 1): الإرشــاد التفسي والتربوي بين الأصالة و التجديد. 


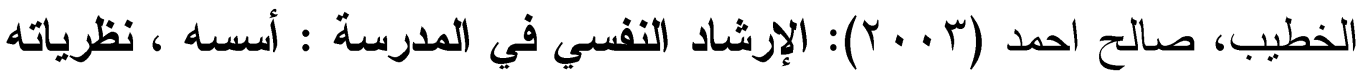
، تطبيقاته، دار الكتاب الجامعي، الامار ات العربية المتحدة.

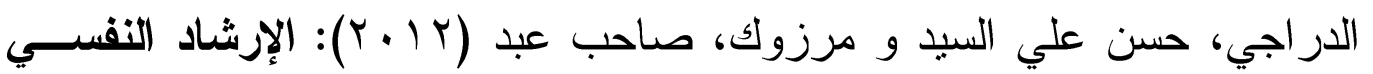
و الصحة النفسية، مكتب نور الحسن للطباعة، بغداد.

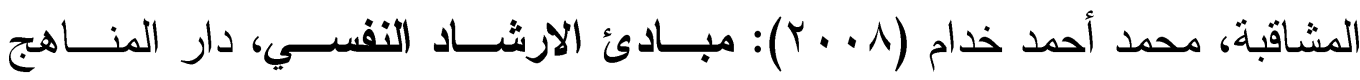
للطباعة و النشر، عمان، الاردن. عقل، محمود عطا حسين (1997) (الإرشاد (النفسي والتربــوي، دار الخريجـي للطباعة و النشر، الرياض.

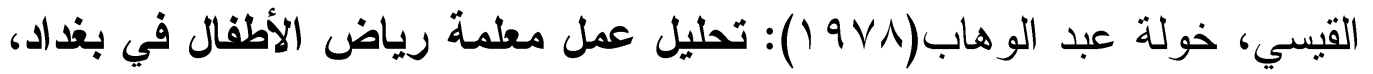
رسالة ماجستير ، كلية التربية، جامعة بغداد.

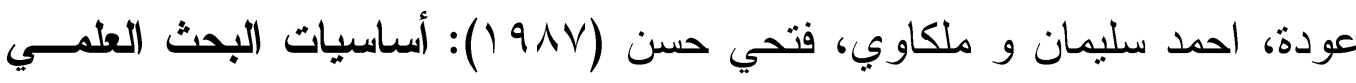
في التربية والعلوم الإسانية (عناصره و مناهجه و التحليل الإحصائي لبياناته)، مكتبة المنار للنشر و التوزيع، دائرة التزبية، جامعة اليرموك.

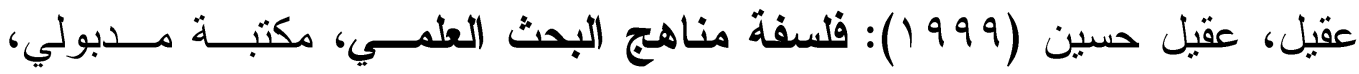
طر ابلس.

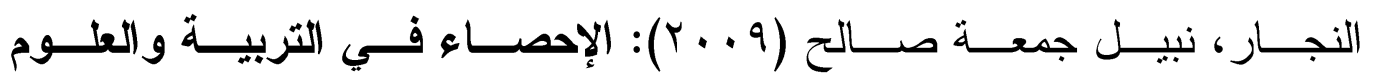

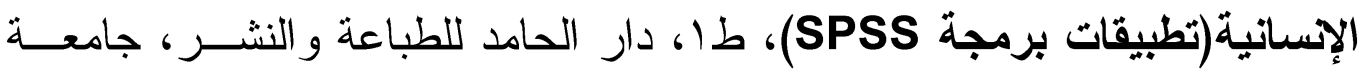

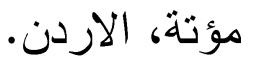

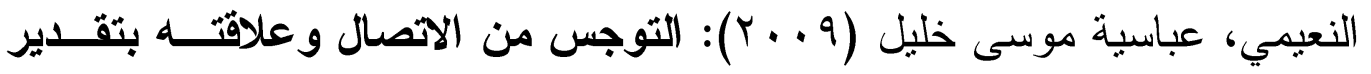

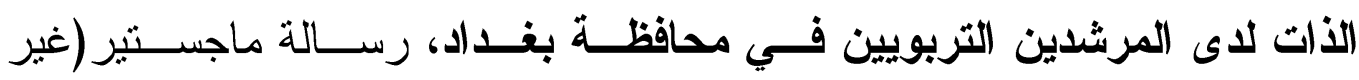
منشورة)، كلية التزبية، الجامعة المستنصرية. 